\title{
ECOLOGICAL CORRELATES OF BASELINE AND MAXIMUM GLUCOCORTICOID CONCENTRATIONS IN WILD FRESHWATER FISH
}

\author{
By \\ Cassia B. Belanger \\ B.Sc., University of Windsor, 2013
}

A thesis submitted to the Faculty of Graduate Studies and Research

in partial fulfillment of the requirements for the degree of

Masters of Science

in

Biology

Carleton University

Ottawa, Ontario

(C) 2015, Cassia B. Belanger 


\section{Dedication}

For my amazing and remarkable family. To my little brothers who always remind me what it means to be responsible, my younger sister who is the most doting partner in crime, and my older sisters who are the most sympathetic confidents. To my mother who has taught me the meaning of hard work and selflessness through example. You never once deny me assistance in my studies or admit you are too busy to go through my notes with me, even though I know you are. To my father who has always been the silent onlooker, yet calm and consistent rock when everyone else is stressing out. When I have nowhere else to go for help, you are always there waiting patiently on the sidelines. Lastly, to my husband Brad: I have required an inhuman amount of patience, understanding, and cheering up in these long two years we have had alone and you have exceeded my expectations. You are what keeps me going when I think I have had enough. 


\section{Abstract}

As wild animals are encountering a rapidly changing world, it is of increasing importance to understand the behavioural and physiological responses associated with these environmental stressors. There are many factors that can potentially influence glucocorticoids (GCs) and the stress response including habitat quality, conspecific density and season which were studied in this thesis. I used freshwater fish to examine how these factors were associated with baseline, maximum and responsiveness of cortisol, the primary GC in teleost fish. Using pumpkinseed (Lepomis gibbosus) collected from limnetic and littoral habitats I tested whether glucose and cortisol baseline, maximum, and responsiveness concentrations varied relative to habitat complexity (i.e. from no substrate or vegetation to a mixture of substrate and various degrees of vegetative cover) and conspecific density experienced following a standardized air stressor. Overall, habitat complexity and conspecific density had no significant effect on the GC stress response but during the habitat experiment the fish collected from the littoral site had significantly higher concentrations of maximum glucose, glucose responsiveness, and maximum cortisol levels. Using central mudminnow (Umbra limi) collected from two nearby streams differing in habitat quality, I tested whether baseline and maximum cortisol levels varied relative to habitat quality and season. Overall, habitat quality had no significant effect on baseline or maximum cortisol levels but there was a significant difference across seasons. The results of this study identify ecological correlates of GC concentrations in wild freshwater fish. Specifically, this body of work indicates that polymorphism and season should be taken into consideration for stress-related studies. Moreover, the lack of association of GCs in fish samples from habitats of differing quality emphasizes that human-perceived differences in habitat quality may not yield individual-level differences in stress. 


\section{Acknowledgements}

I would like to thank my supervisor, S.J. Cooke, for much guidance, feedback and support throughout the completion of my master's thesis. I also thank my co-authors, T.W. Moon, M.N. Vera-Chang, J.Midwood, and C.D. Suski for their feedback and contributions as well as the guidance and assistance in the lab. Further thanks are extended to M.N. Vera-Chang for her flexibility in scheduling, hard work in obtaining my final results, and helping me get established at the University of Ottawa. I would like to thank J. Midwood, M. Cvetkovic, A. Burt, C. Delle Palme, T. Peat, D. Struthers, S. Bliss, and C. Crawford for all of their help with electroshocking at Watts Creek throughout the year. I would further like to thank S. Bliss for helping me get settled into my master's program and introducing me to the lab and Watts Creek area. There is much appreciation for all of the help and enthusiasm I received at the Queen's University Biology Station by K. Dufour, B. Sullivan, S. Jain-Schlaepfer, and C. Cock. I also give thanks to my friends and family for their encouragement and support. All research was conducted in accordance with Scientific Collection Permits provided by the Ontario Ministry of Natural Resources and Forestry and animal care protocols from the Canadian Council of Animal Care. Cooke and Moon are supported by the NSERC Discovery Grants program and Cooke is further supported by the Canada Research Chairs program. The Canada Foundation for Innovation and the Ontario Ministry of Research and Innovation provided funding for the research vessel used in the study at the Queen's University Biology Station. The National Capital Commission provided financial support and land access for the study at Watts Creek in Kanata, Ontario. 


\section{Co-Authorship}

Chapter 2: Pumpkinseed from littoral and limnetic waters differ in glucocorticoid responsiveness independent of habitat complexity and presence of conspecifics. Cassia B. Belanger, Marilyn N. Vera-Chang, Thomas W. Moon, and Steven J. Cooke

While this study is my own, the research was undertaken as part of a collaborative effort and each co-author played a valuable role in its completion. The project was conceived by Belanger and Cooke. Fieldwork was conducted by Belanger and lab work was completed by Belanger and Vera-Chang. All data analysis was conducted by Belanger. Data were interpreted by Belanger with input from Cooke. All writing was completed by Belanger with comments and feedback provided by all co-authors.

Chapter 3: Seasonal variation in baseline and maximum whole-body glucocorticoid concentrations in a small-bodied stream fish independent of habitat quality. Cassia B. Belanger, Marilyn N. Vera-Chang, Thomas W. Moon, Jon D. Midwood, Cory D. Suski, and Steven J. Cooke

While this study is my own, the research was undertaken as part of a collaborative effort and each co-author played a valuable role in its completion. The project was conceived by Belanger, Midwood, Suski, and Cooke. Fieldwork was conducted by Belanger and Midwood and lab work was completed by Belanger and Vera-Chang. All data analysis was conducted by Belanger. Data were interpreted by Belanger with input from Cooke. All writing was completed by Belanger with comments and feedback provided by Vera-Chang, Moon, Midwood, Suski, and Cooke. 


\section{Table of Contents}

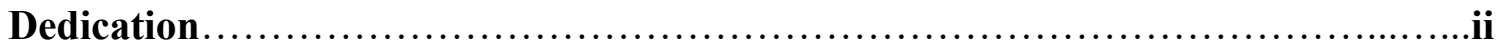

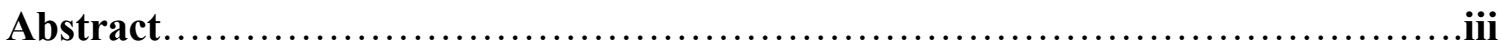

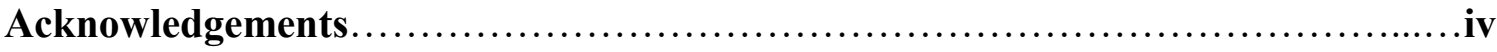

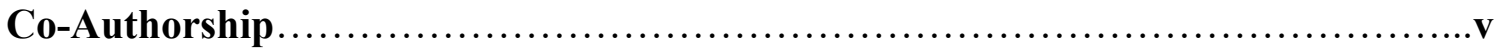

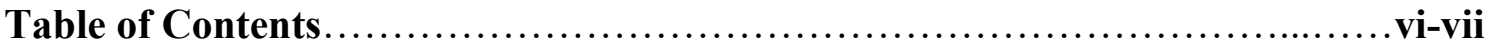

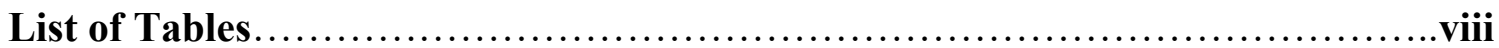

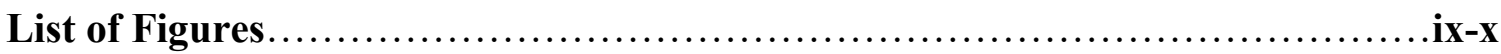

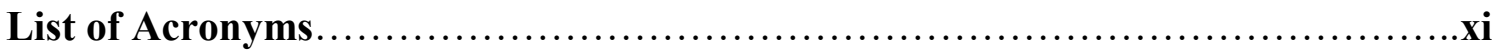

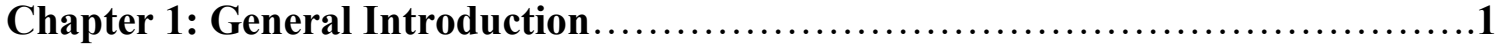

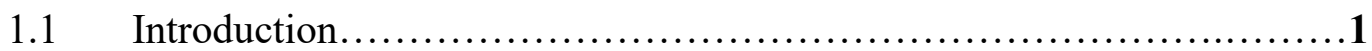

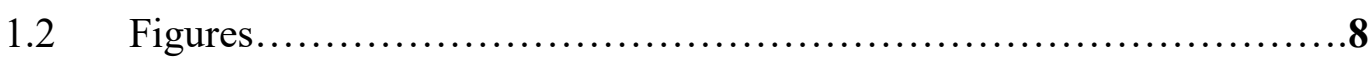

Chapter 2: Pumpkinseed from Littoral and Limnetic Waters Differ in Glucocorticoid Responsiveness Independent of Habitat Complexity and Presence of

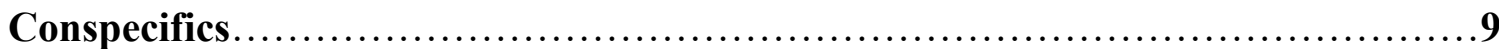

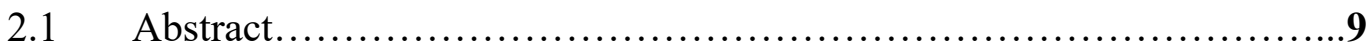

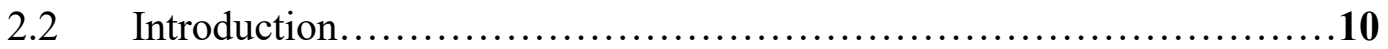

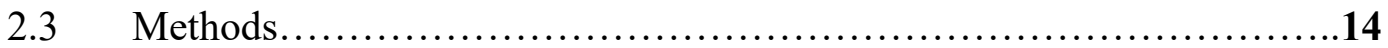

2.3.1 Habitat Complexity Experiment.............................14

2.3.2 Conspecific Density Experiment...............................16

2.3.3 Cortisol Assays.............................................16

2.3.4 Statistical Analysis.......................................16

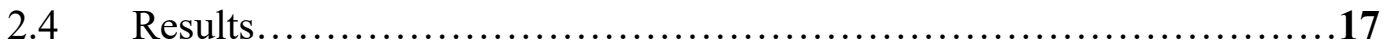

2.4.1 Habitat Complexity Experiment...............................17

2.4.2 Conspecific Density Experiment............................18

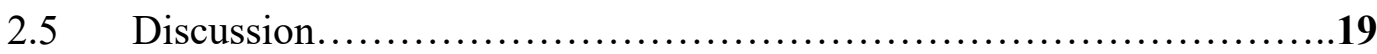

2.5.1 Habitat Complexity Experiment................................20

2.5.2 Conspecific Density Experiment...............................21

2.5.3 Synthesis and Conclusions..................................22

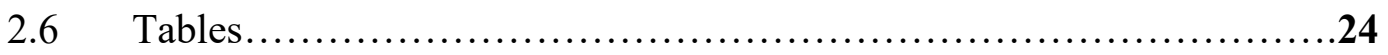

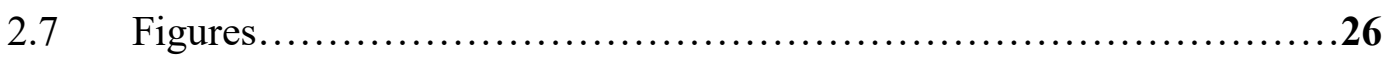

Chapter 3: Seasonal Variation in Baseline and Maximum Whole-Body Glucocorticoid Concentrations in a Small-Bodied Stream Fish Independent of

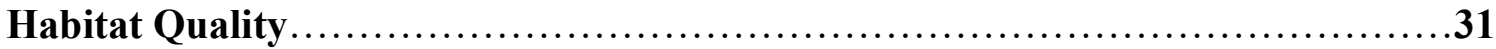

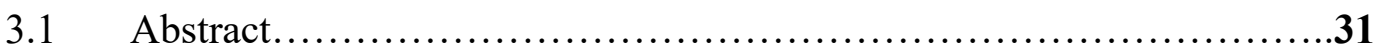

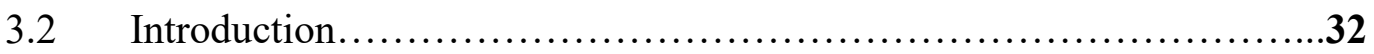

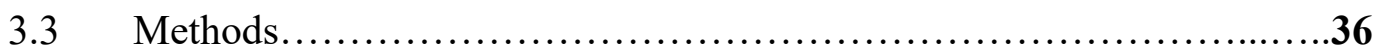

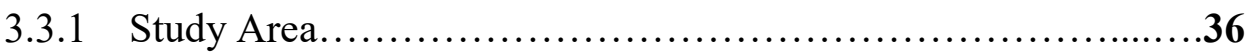

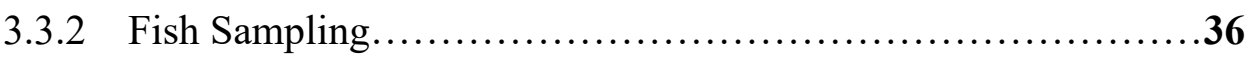


3.3.3 Cortisol Analysis............................................37

3.3.4 Statistical Analysis............................................38

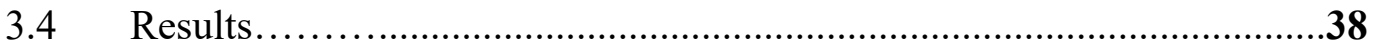

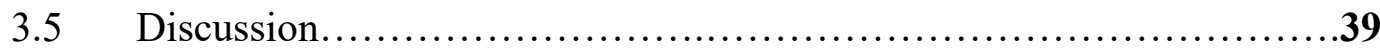

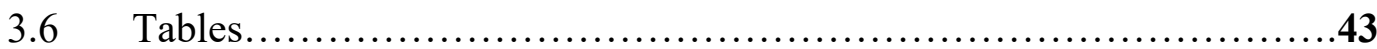

$3.7 \quad$ Figures.......................................................... 44

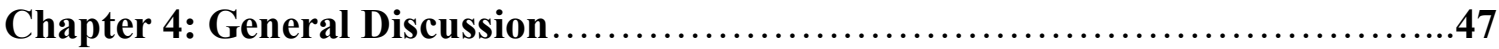

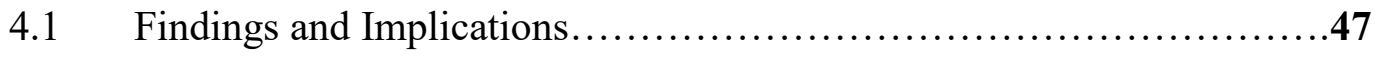

$4.2 \quad$ Future Directions....................................................

4.3 Conclusions....................................................

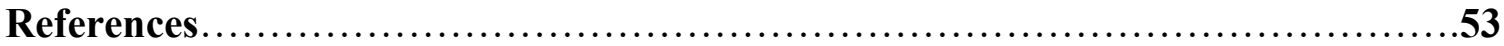




\section{List of Tables}

Table 2.1: $\quad$ Results of a two-way ANOVA with habitat type, capture site and the interaction as the independent variables and baseline, elevated and response levels of both cortisol and glucose as the targeted dependent variables. Comparing stress level proxies of pumpkinseed fish (Lepomis gibbosus) captured from littoral and limnetic sites on Lake Opinicon prior to and following a standardized air stressor. Significant values $(\mathrm{P}<0.05)$ are shown in bold-italics, near-significant values $(0.05<\mathrm{P}<0.1)$ are shown in italics

Table 2.2: Results of a two-way ANOVA with conspecific, capture site and the interaction as the independent variables and baseline, elevated and response levels of both cortisol and glucose as the targeted dependent variables. Comparing stress level proxies of pumpkinseed fish (Lepomis gibbosus) captured from littoral and limnetic sites on Lake Opinicon prior to and following a standardized air stressor. Near-significant values $(0.05<\mathrm{P}<0.1)$ are shown in italics

Table 3.1: Results of a two-way ANOVA with capture site and season as the independent variables and weight, baseline cortisol, and maximum cortisol as the measured dependent variables. Comparing pre- and post-stress response of central mudminnow (Umbra limi) collected from Watts creek and Kizell drain to a standardized air stressor. Significant values $(\mathrm{P}<0.05)$ are shown in bolditalics 


\section{List of Figures}

Figure 1.1: The GC stress response. Lower levels of GCs are required for basic survival (shown as basal in dark grey) while regular variations in baseline levels (shown in white) occur due to changes in many factors such as time of day, season, and lifehistory stage. When exposed to a stressor GC concentrations increase (shown in light grey) to maximum levels, resulting in the physiological and behavioural changes associated with the stress response. Stress responsiveness is the difference between the measured maximum GC concentration and the measured baseline GC concentration. Adapted from Busch and Hayward (2009).......... 8

Figure 2.1: $\quad$ Baseline and elevated glucose levels and glucose responsiveness $(\mathrm{mmol} / \mathrm{L})$ for pumpkinseed sunfish collected from littoral and limnetic sites and assigned to four experimental habitat treatments (only water $(\mathrm{N})$, cobble substrate $(\mathrm{S})$, cobble substrate with $50 \%$ vegetative cover $(\mathrm{H})$, and cobble substrate with $90 \%$ vegetative cover $(\mathrm{V}))$. Data presented are means \pm 1 standard error; $\mathrm{n}=62$ and 55 for limnetic and littoral sites, respectively.......................26

Figure 2.2: Baseline and elevated cortisol levels and cortisol responsiveness $(\mathrm{ng} / \mathrm{mL})$ for pumpkinseed sunfish collected from littoral and limnetic sites and assigned to four experimental habitat treatments (only water $(\mathrm{N})$, cobble substrate $(\mathrm{S})$, cobble substrate with $50 \%$ vegetative cover $(\mathrm{H})$, and cobble substrate with $90 \%$ vegetative cover(V)). Data presented are means \pm 1 standard error; $n=62$ and 55 for limnetic and littoral sites, respectively.........................27

Figure 2.3: Baseline and elevated glucose levels and glucose responsiveness $(\mathrm{mmol} / \mathrm{L})$ for pumpkinseed sunfish collected from littoral and limnetic sites and assigned to three experimental conspecific treatments (no other conspecifics (A), one other conspecific (O), and five other conspecifics $(\mathrm{F})$ ). Data presented are means \pm 1 standard error; $\mathrm{n}=51$ and 50 for limnetic and littoral sites, respectively

Figure 2.4: Baseline and elevated cortisol levels and cortisol responsiveness $(\mathrm{ng} / \mathrm{mL})$ for pumpkinseed sunfish collected from littoral and limnetic sites and assigned to three conspecific treatments (no other conspecifics (A), one other conspecific $(\mathrm{O})$, and five other conspecifics $(\mathrm{F})$ ). Data presented are means \pm 1 standard error; $\mathrm{n}=$ 51 and 50 for limnetic and littoral sites, respectively.....................29

Figure 2.5: Lake Opinicon $\left(44^{\circ} 56^{\prime} \mathrm{N}, 76^{\circ} 33^{\prime} \mathrm{W}\right)$ in Ontario, Canada where this study took 
place. The entire lake was utilized for angling of pumpkinseed and the star denotes the location of Queen's University Biology Station. Taken from Pullen (2013).

Figure 3.1: Baseline cortisol (ng/g) for central mudminnow collected from Watts creek and Kizell drain over four seasons (winter, W; fall, F; spring, S; summer, U). Winter and summer baseline cortisol values differed significantly $(\mathrm{P}<0.01)$ from the fall and spring months. Data presented are means \pm 1 standard error; $\mathrm{n}=10$ for Watts and Kizell in each of the seasons...................................43

Figure 3.2: Elevated cortisol (ng/g) for central mudminnow collected from Watts creek and Kizell drain over four seasons (winter, W; fall, F; spring, S; summer, U). Summer elevated cortisol levels differed significantly $(\mathrm{P}<0.01)$ from spring levels. Data presented are means \pm 1 standard error; $n=10$ for Watts and Kizell in fall spring and summer, $\mathrm{n}=9$ for Watts and Kizell in winter. 44

Figure 3.3: The Watts Creek watershed where this study took place. Sampling occurred 150 $m$ upstream from the confluence in both Kizell Drain and Watts Creek. Water flows from west to east in Kizell Drain and south to north in Watts Creek. Taken

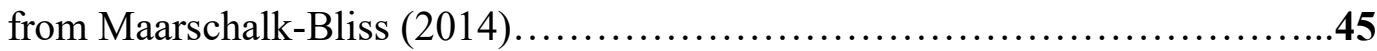




\section{List of Acronyms}

ANOVA: Analysis of Variance

Df: Degrees of Freedom

GC: Glucocorticoid

HPA: Hypothalamic-Pituitary-Adrenal

HPI: Hypothalamic-Pituitary-Interrenal

K: Fulton's Condition Factor

SD: Standard Deviation

NCC: National Capital Commission

CRH: Corticotropin-releasing hormone

ACTH: Adrenocorticotropic hormone 


\section{Chapter 1: General Introduction}

\subsection{Introduction}

With the world's population growing exponentially, the impact human activity has on the environment is of increasing interest and concern. Much of the world's terrestrial and freshwater surface is already under the influence of human development (Vitousek et al. 1997). Fresh water is one of the most valuable natural resources on earth yet is also one of the most affected by human activities and associated climate change (Dudgeon et al. 2006; Vörösmarty 2010). Freshwater species (fish, amphibians, reptiles, and mammals) comprise approximately one third of all existing vertebrate species, a clear indication that much of the world's biodiversity is affected by alterations to freshwater systems (Dudgeon et al. 2006). Overexploitation, pollution, modification of flow patterns, habitat degradation, and introduction of exotic species, all of which have human origins, are some of the many factors that directly influence and threaten freshwater systems worldwide (Dudgeon et al. 2006). In addition to changes to the physical environment, anthropogenically influenced climate change in terms of temperature, extreme weather events, and seasonal patterns can also be a major challenge with which wild animals must adjust to or else suffer the consequences (Easterling et al. 2000). Measures such as reproductive success, individual survival, species abundance, distribution, and body condition have been used as indicators of habitat quality in past studies (Johnson 2007). One such measurement that has seen recent popularity is the measure of glucocorticoids (GCs) in species as an indication of stress (Busch and Hayward 2009; Sheriff et al. 2011). This estimate of stress 
is then used to indicate a species or population that is in a better or poorer condition as a result of the current environmental conditions.

Due to recent advances in minimally invasive sampling techniques that can be used in the field (Busch and Hayward 2009), measurements of hormones in the wild are more frequently being used as markers for stress. Habitat quality is capable of influencing an organism's physiology (Huey 1991; Wingfield 2005) so there is great potential in using physiological measures to infer environmental condition in a conservation setting (Dale and Beyeler 2001; Busch and Hayward 2009). One of these classes of hormones are GCs, which are increasingly being employed as indicators of individual or population stress level and furthermore as indicators of individual or population condition (Wikelski and Cooke 2006; Bonier et al. 2009a). GCs are stress hormones that are present in all vertebrates (Sapolsky et al. 2000). When presented with a stressor two pathways responsible for mobilization and allocation of energy stores are stimulated: the hypothalamic-autonomic nervous system-adrenal medulla axis which ultimately releases epinephrine and the hypothalamic-pituitary-adrenal (HPA) axis (hypothalamic-pituitary-interrenal (HPI) axis in fish, reptiles and amphibians) which ultimately releases GCs (Chrousos and Gold 1992; Bonga, 1997; Reeder and Kramer 2005). In fish, once a stimulus has been perceived as a stressor by the organism's sensory system the hypothalamus releases corticotropin-releasing hormone $(\mathrm{CRH})$ which stimulates the anterior pituitary to produce adrenocorticotropic hormone (ACTH) (Bonga 1997). In fish, ACTH acts on interrenal tissue which ultimately releases glucocorticoids, primarily cortisol in teleost fishes (Bonga 1997). At low concentrations, regularly observed in organisms, GCs bind to a high-affinity receptor, assisting in general, daily energy regulation (Busch and Hayward 2009). However, when GC secretion increases in response to a stressor GCs begin to saturate the high-affinity 
receptors and then bind to lower-affinity receptors, resulting in behavioural and physiological changes (Sapolsky et al. 2000; Romero 2004).

Baseline level GCs are required for survival (Landys et al. 2006) but can be employed as indicators of individual or population health. Baseline GCs are generally quantified within three minutes of capture (Romero and Reed 2005) before concentrations have risen in response to the handling stressor. Lower baseline GC concentrations are generally accepted as an indicator of an individual or population in better condition while higher baseline GC concentrations are assumed to indicate an individual in poorer condition (Bonier et al. 2009a; Busch and Hayward 2009). Elevated GC levels are thought to initiate a redirection of energy away from long-term processes and towards immediate survival (Sapolsky et al. 2000). Therefore, it is reasonable to associate high baseline GC levels with lower overall fitness due to this reallocation of energy (Bonier et al. 2009). In addition, individuals with higher baseline GC levels could indicate that they perceive their current situation as stressful or challenging (Husak and Moore 2008; Bonier et al. 2009a). However, not all studies that examine both baseline GC levels and fitness proxies find the same correlation. In general, baseline GCs can be used to estimate condition or fitness but the same relationship is not present in all cases or in all species (Bonier et al. 2009a).

GC levels are elevated following exposure to a stressor and, when experienced for a limited amount of time, assist the individual in responding appropriately to the challenge (Wingfield et al. 1998; Wingfield and Romero 2001; Breuner et al. 2008; Bush and Hayward 2009). Elevated GCs do this through many facets, some of which act by increasing cardiac tone, blood glucose levels, and cerebral blood flow as well as regulating the immune system (Wingfield et al. 1998; Busch and Hayward 2009). While increasing behaviours that promote immediate survival, elevated GCs simultaneously inhibit behaviours that would distract from 
immediate survival (e.g. reproduction, foraging, etc.) (Wingfield et al. 1998; Busch and Hayward 2009). If the stressor remains for an extended period of time, GC elevation can become chronic and harmful to the organism (Busch and Hayward 2009; Romero et al. 2009; Boonstra 2013), though much of the research supporting this claim comes from laboratory studies (Dantzer et al. 2014). In the long-term, elevated GCs can result in decreased immune activity, growth, reproduction, and survival (Breuner et al. 2008; Busch and Hayward 2009). Maximum GC levels are measured following exposure to a stressor (Sapolsky et al. 2000; Romero et al. 2008). The time required for GC levels to elevate to peak values following a stressor differs across species and should be validated prior to interpreting data for that species. The difference between the maximum and baseline GC concentrations in an individual is commonly referred to as the "stress responsiveness" (Figure 1.1) and can also be employed as an indicator of individual fitness (Breuner et al. 2008). As already mentioned, the acute stress response is generally considered to be adaptive but a good stress response is likely one with a rapid elevation of GCs followed by a prompt decrease back to baseline levels (Breuner et al. 2008; Dantzer et al. 2014). In this way, the organism in question would be able to mount a suitable response to the challenge at hand while preventing the costs of chronic stress (Breuner et al. 2008; Angelier and Wingfield 2013). Through baseline GCs, maximum GCs, and GC responsiveness it is possible to make inferences on the condition of individuals and further extrapolate this to identify habitats of better or poorer quality (Dantzer et al. 2014).

There are multiple factors that have the capability of altering the stress response. Time of day, season, sex, reproductive status, age, social ranking, habitat quality, food abundance, predator pressure, and crowding can all influence how an individual responds to a challenge (Fusani 2008; Dantzer et al. 2014). In a review done by Romero (2002) it was found that not 
only do GCs change regularly through the day but in the majority of studies there is also an annual rhythm to GC concentrations with them typically peaking during the breeding season (though fish were not covered in this review). Sex can influence GC levels in both directions with male desert tortoises (Gopherus agassizii) consistently exhibited significantly higher baseline GC levels than females (Lance et al. 2001) while it was female American kestrels (Falco sparverius) that exhibited higher baseline GC levels than males in a study by Strasser and Heath (2013). Though it is not often taken into consideration, reproductive status (i.e. breeding, pregnant, or caring for young) can have an influence on the stress response as it did in maned wolves (Chrysocyon brachyurus) with maximum GC levels higher in males and non-breeding females than in breeding females (Spercoski et al. 2012). As individuals age they tend to display an amplified response to a stressor (Dantzer et al. 2014). This pattern of GC response increasing with age has been observed in Magellanic penguins (Spheniscus magellanicus) (Walker et al. 2005b), northern mockingbirds (Mimus polyglottos) (Sims and Holberton 2000), and American kestrels (Falco sparverius) (Love et al. 2003). Social ranking had an effect on baseline and maximal GCs in squirrel monkeys (Saimiri sciureus) with dominant males demonstrating higher baseline GCs and lower GC responsiveness (Coe et al. 1979). Social ranking, however, can be complex as the causality is unclear. It is possible that the differences in stress response are the reason for the social ranking but the opposite is also possible: that the social ranking resulted in a change in stress response. Habitat quality has been seen to have a variety of effects on the stress response from no effect in eastern hellbenders (Cryptobranchus alleganiensis) (Hopkins and DuRant 2011), to a difference in some seasons in American redstarts (Setophaga ruticilla) (Marra and Holberton 1998), to a significant difference in the degu (Octodon degus) (Bauer et al. 2013). Areas with high food abundance resulted in lower baseline and maximum GC levels in 
the degu (Bauer et al. 2013) and areas with higher predator pressure elicited lower GC responsiveness in a poeciliid fish (Brachyrhaphis episcopi) (Archard et al. 2012). Red porgy (Pagrus pagrus) displayed higher baseline GCs but no difference in responsiveness when exposed to 3 weeks of overcrowding (Rotllant and Tort 1997). All of these factors, and others, can influence release of GCs alone and in interaction with others, which makes interpreting results complex. In general, there is relatively little known about the ecological correlates of GCs in fish relative to other taxa.

The first location of interest in this thesis was Lake Opinicon on which the Queen's University Biology Station is situated, approximately $100 \mathrm{~km}$ south of the Ottawa area. This lake is commonly researched, contained the fish species of interest for this thesis, and permitted the use of the required limnetic and littoral sites for this study. The second location of interest in this thesis was the Watts Creek watershed which is located in Kanata, the largest suburb of the Ottawa region in Ontario, Canada. The watershed is largely located in a stretch of the National Capital Commission (NCC) greenbelt area and consists of Watts Creek and the Kizell Municipal Drain, tributaries of the Ottawa River. Kizell Drain receives stormwater runoff from the Kanata area and is less sinuous, narrower, shallower, and has less in-stream structure than Watts Creek (Maarschalk-Bliss, 2014; Bliss et al. 2015). Due to these differences, Kizell is considered to be the more disturbed habitat when compared with Watts (Goldstein and Meador 2005; Bliss et al. 2015). While work has been done by Bliss and colleagues (2015) to observe the current conditions of the watershed through fish movement and assemblage, there have not been studies on the difference in individual condition between Watts Creek and Kizell Drain. The effects of further urbanization in the area can be better understood by studying the variation in individual physiology between the two tributaries. 
The general objective of this thesis was to evaluate how various factors are associated with the stress response in freshwater fish. In Chapter 2, wild pumpkinseed sunfish (Lepomis gibbosus) were used to study the variation in GCs (cortisol in fish) between fish sampled from limnetic and littoral sites in response to different habitat complexity and conspecific density. This was accomplished through blood samples collected immediately after capture and after a recovery period in treatments varying in habitat complexity and conspecific density following a standardized air stressor. I hypothesized that fish collected from the littoral site would display lower GC responsiveness when exposed to higher habitat complexity and higher conspecific density while fish collected from the limnetic site would display lower GC responsiveness when exposed to lower habitat complexity and lower conspecific density. In Chapter 3, wild central mudminnow (Umbra limi) were used to study the variation in cortisol between fish sampled from Watts Creek and Kizell Drain. This was accomplished through electroshocking and whole-body cortisol analysis of fish that were stunned immediately following capture (i.e. baseline levels) and fish that were stunned following a standardized air stressor (i.e. maximum levels). I hypothesized that fish from Kizell Drain, the more degraded habitat, would exhibit higher baseline and lower maximal cortisol levels than fish from Watts Creek. The information collected in these two studies will help to better understand the many factors that can influence the stress response in freshwater fish and can be used for conservation management plans and further studies in the future. 


\subsection{Figures}

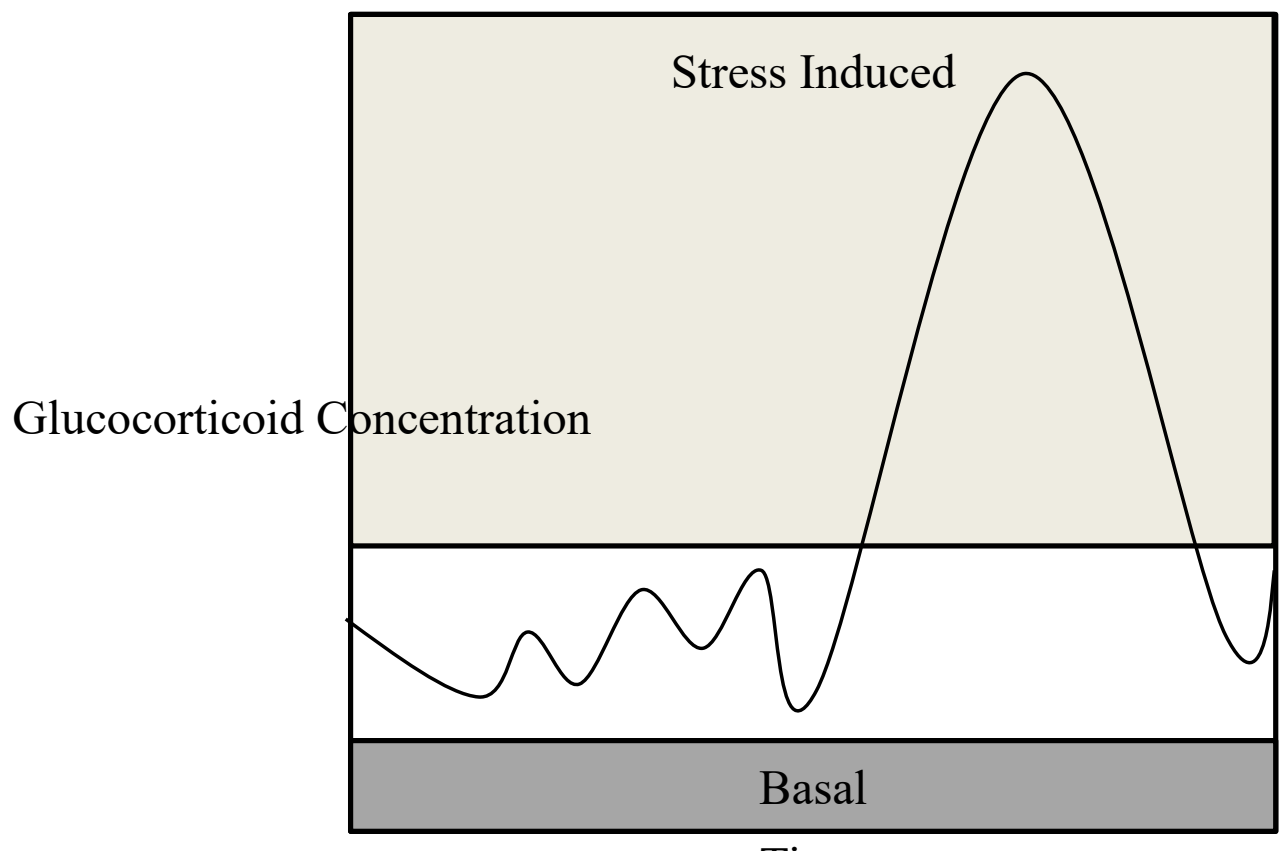

Time

Figure 1.1: The GC stress response. Lower levels of GCs are required for basic survival (shown as basal in dark grey) while regular variations in baseline levels (shown in white) occur due to changes in many factors such as time of day, season, and life-history stage. When exposed to a stressor GC concentrations increase (shown in light grey) to maximum levels, resulting in the physiological and behavioural changes associated with the stress response. Stress responsiveness is the difference between the measured maximum GC concentration and the measured baseline GC concentration. Adapted from Busch and Hayward (2009). 


\section{Chapter 2: Pumpkinseed from Littoral and Limnetic Waters Differ in Glucocorticoid Stress Responsiveness Independent of Habitat Complexity and Presence of Conspecifics}

\subsection{Abstract}

In the face of a changing world, there has been increasing interest in the behavioural and physiological responses of wild animals to stressors. Many factors can influence glucocorticoid (GC) stress responsiveness but two that have not been extensively studied are habitat complexity and the presence of other conspecifics. Using wild pumpkinseed (Lepomis gibbosus) collected from limnetic and littoral environments we tested the hypothesis that glucose and cortisol responsiveness varied relative to habitat complexity and the number of conspecifics during the recovery period following a standardized air stressor. Overall, habitat complexity and conspecific density did not have a significant effect on GC responsiveness. However, in the habitat experiment we observed that fish collected from the littoral site had significantly $(\mathrm{P}<0.05)$ higher concentrations of maximum glucose, glucose responsiveness, and maximum cortisol levels as well as nearly significant $(\mathrm{P}<0.1)$ higher cortisol responsiveness. The fact that similar patterns were not observed between limnetic and littoral fish in the conspecific density study, which was conducted later in the season, suggests that there could be a seasonal aspect to differences between limnetic and littoral inhabitants. Our results indicate that polymorphic species may respond differently to stressors, possibly on a seasonal basis. As such, those factors should be considered in stress-related studies. Although no strong evidence of habitat or densityspecific effects on GC responsiveness was found, studies on species deemed as habitat specialists 
and species that are solely solitary or gregarious would represent logical future research priorities for understanding ecologically-relevant factors that influence baseline GCs and GC responsiveness.

\subsection{Introduction}

The endocrine system of wild animals plays an important role in mediating life-history trade-offs and linking organisms to their environment (Zera and Harshman 2001; Ricklefs and Wikelski 2002). This is particularly true for glucocorticoid (GC) steroid hormones (Wingfield et al. 1998). GCs are prevalent in all vertebrates and are released when the hypothalamic-pituitaryadrenal (HPA) axis (the hypothalamic-pituitary-interrenal (HPI) axis in fishes) is activated in response to a perceived or actual stressor (Sapolsky et al. 2000). In the short term, the GC stress response is beneficial and necessary to react appropriately to a challenge (Wingfield et al. 1998; Wingfield and Romero 2001). GC release triggers physiological and behavioural changes that promote immediate survival and suspend activities deemed temporarily unnecessary (Sapolsky et al. 2000). However, chronic elevation of GCs may be harmful to an individual's health, reproductive success, and overall survival (Romero et al. 2009; Boonstra 2013). Baseline GC levels are generally measured within three minutes of capture (Romero and Reed 2005) and maximal GC levels can be measured once the HPA (or HPI) axis has reacted to the stressor. The stress response (often termed "stress responsiveness") is the difference between the maximal and baseline concentrations of GCs (Breuner et al. 2008). It is generally accepted that a low baseline GC concentration indicates a fit individual (Bonier et al. 2009a; Busch and Hayward 2009) and a good stress response is one that involves a rapid increase in GCs followed by a quick return to 
baseline levels (Breuner et al. 2008). A response such as this would enable an organism to respond appropriately to a challenge while limiting the negative consequences associated with the chronic elevation of GCs (Angelier and Wingfield 2013).

Although once the domain of laboratory-bound physiologists and endocrinologists, in recent years there has been increasing interest in studying the endocrinology of animals in the wild to fully comprehend how humans are altering the natural world (Walker et al. 2005a; Dantzer et al. 2014) and to understand the ecology of stress (Boonstra 2013) and the endocrine basis of life-history trade-offs (Ricklefs and Wikelski 2002). Indeed, it is relatively easy to collect non-lethal and/or non-invasive tissue samples (e.g. blood, feathers, hair) or waste products (e.g. fecal matter, respiratory output) and quantify GCs (Sheriff et al. 2011) in what is often termed "field endocrinology" (Walker et al. 2005a). However, interpretation of findings can be quite challenging given that numerous factors can influence baseline and stress-induced GC levels (Fusani 2008; Dantzer et al. 2014). For example, the stress response can vary among conspecifics based on age (e.g. Walker et al. 2005b), sex (e.g. Lance et al. 2001), reproductive status (e.g. Gesquiere et al. 2008), genetics (e.g. Evans et al. 2006), and social rank (e.g. Coe et al. 1979). Environmental factors such as habitat quality (e.g. Newcomb Homan et al. 2003), season (e.g. Breuner and Orchinik 2001), food abundance (e.g. Kitaysky et al. 1999), and predator pressure (e.g. Archard et al. 2012) can also influence the GC response.

Two factors that have been poorly studied in the context of GCs which can vary between ecological systems are habitat complexity and social exposure (i.e. presence of conspecifics). Elements of habitat quality related to deforestation and fragmentation and their impacts on baseline GCs and GC responsiveness have been studied but results have been varied (e.g. Wasser et al. 1997; Newcomb Homan et al. 2003; Suorsa et al. 2003; Tempel and Gutierrez 2003). Less 
is known about how more natural levels of variation in habitat quality (e.g. ranging from noncomplex to highly complex habitats) influence GC levels and responsiveness. The exception arises from a study of Jundiá (Rhamdia quelen) where it was revealed that the amount of both substrate and cover available can influence the stress response of fish once exposed to a perturbation (Barcellos et al. 2009). It is presumed that, when presented with a stressor, individuals living in habitats of higher quality are better equipped to respond appropriately to the stressor than those in sub-optimal habitats (Nagrodski et al. 2013). In terms of social exposure, isolation for a gregarious species can affect their health and has been reported to increase baseline GC levels in some cases (Hawkley et al. 2012). For example, in Zebra finches (Taeniopygia guttata) GCs were elevated during mate separation yet returned to baseline levels when reunited with the same opposite-sex partner (Remage-Healey et al. 2003). Social species depend on mates or the group dynamic for protection, food gathering or hunting, rearing of young, and more. This phenomenon where the presence of social companions can be beneficial for the individual at many levels, such as reducing the physiological reactions to a challenge, is commonly referred to as "social buffering" (Hennessy et al. 2009). Social buffering can be seen in mammal and avian species (Hennessy et al. 2009) with very few studies focusing on fish as model species (e.g. Gilmour et al. 2005; Allen et al. 2009).

Using wild pumpkinseed sunfish (Lepomis gibbosus) as the model species, baseline and elevated glucose and cortisol levels were quantified in response to different habitat and social exposure experienced following a standardized air stressor. The pumpkinseed sunfish is a common species in the family Centrarchidae widely distributed across North America. They typically feed on hard-bodied prey in the littoral zone (Osenberg et al. 1992) but can also be found foraging in more offshore limnetic habitats (Robinson and Wilson 1996). We were able to 
exploit the fact that pumpkinseed could be captured from these two discrete environments in the same waterbody (i.e. littoral vs limnetic) to evaluate the role of capture environment on baseline GCs and responsiveness. Pumpkinseed display polymorphism (the presence of multiple phenotypes within one species) which can be seen in their gill raker and jaw structure and coincides with a difference in diet (Gillespie and Fox 2003). Pumpkinseed from littoral and limnetic habitats can typically be differentiated morphologically and in terms of life-history (Gillespie and Fox, 2003) owing largely to trophic specialization (Robinson and Wilson 1996). We operated under the hypothesis that the stress response is magnified for animals that are "recovered" in habitats and social environments that are dissimilar to those from which they are captured. Pumpkinseed from littoral regions would regularly interact with substrate and high levels of habitat structure (i.e. macrophytes) as well as large numbers of conspecifics in nearshore schools while fish from limnetic regions would be less likely to interact with substrate or vegetative cover and would typically be more solitary (Warren 2009). We conducted two experiments. First, we tested the hypothesis that a habitat with a higher degree of complexity results in lower GC responsiveness for fish collected from a littoral site while a habitat with a lower degree of complexity results in lower $\mathrm{GC}$ responsiveness for fish collected from a limnetic site. Second, we tested the hypothesis that a higher conspecific density results in lower GC responsiveness for fish collected from a littoral site while a lower conspecific density results in lower GC responsiveness for fish collected from a limnetic site. 


\subsection{Methods}

\subsubsection{Habitat Complexity Experiment}

This study was performed from June 26 through July 3, 2014 at the Queen's University Biological Station located approximately $50 \mathrm{~km}$ north of Kingston, ON, Canada. Working from a $6 \mathrm{~m}$ research vessel, pumpkinseed sunfish were collected by angling from Lake Opinicon $\left(44^{\circ} 56^{\prime} \mathrm{N}, 76^{\circ} 33^{\prime} \mathrm{W}\right)$ from both limnetic $(\mathrm{n}=62)$ and littoral $(\mathrm{n}=55)$ locations. Surface water temperature throughout the nine day period remained fairly stable $\left(25-27^{\circ} \mathrm{C}\right)$. All fish were captured on small pieces of dew worm on barbless hooks. Only fish that were between 150 and $238 \mathrm{~mm}$ in size, hooked in the jaw and showed no evidence of bleeding or other angling-related injury were included. All fish were fought for $10 \mathrm{sec}$ to standardize the capture stressor. Upon landing, the fish underwent a three minute standardized air stressor. Using an air stressor, which typically involves leaving the fish in a moistened container without water for a short period of a time, is a common method used among fish studies to elicit the stress response. During the air exposure period, a baseline blood sample was obtained using a $1 \mathrm{~mL}$ heparinised syringe (Becton, Dickinson and Company) and a 25 gauge, 11/2 inch needle (Becton, Dickinson and Company). Approximately 0.2-0.3 mL of blood was taken from the caudal vasculature, directly posterior to the anal fin. Any fish that was not bled within the $3 \mathrm{~min}$ air exposure period was excluded from the experiment. If, after the blood sampling, $3 \mathrm{~min}$ of air exposure had not yet elapsed, fish were placed in a bucket with a moistened rubber mat for the remainder of the three minutes. Once the three minutes had elapsed, fish were introduced into one of four treatment tanks. All treatments took place in a $68 \mathrm{~L}$ Rubbermaid bin $(64.77 \mathrm{~cm} \times 44.45 \mathrm{~cm} \times 39.05 \mathrm{~cm})$ filled to $30 \mathrm{~cm}$ with ambient water collected from the lake that was replaced after every trial run. 
The four treatments included a bin with just water, a bin with substrate in the form of cobble (approximately $2.5 \mathrm{~cm} \times 2.5 \mathrm{~cm} \times 2.5 \mathrm{~cm}$ cobble and covering the entire bottom of the bin), a bin with cobble substrate and approximately $50 \%$ vegetative cover collected from the lake (a combination of Myriophyllum and Potamogeton species), and a bin with cobble substrate and approximately $90 \%$ vegetative cover. A lid with holes was placed on top of the bin and the assigned fish was left for 42 minutes (45 minutes total from start of air exposure). During that period, water temperatures remained stable and disturbance (e.g. boat motor noise, talking) was minimized. Working with the congeneric bluegill sunfish (Lepomis macrochirus), Cook et al. (2012) reported that cortisol levels peaked at that time period. Following the 42 minutes, the fish were removed and a second blood sample was taken in the same manner as the first. If this second sample was not completed within two minutes then the fish was disqualified from the study and the first blood sample disposed of. This second blood sample represented maximum cortisol levels while the first blood sample represented baseline concentrations.

Prior to being returned to the lake, total length (to the nearest $\mathrm{mm}$ ) was recorded and the caudal fin was clipped in case of recapture. All blood samples were kept in capped syringes and placed in an ice-water slurry for no longer than two hours. Whole blood glucose levels were read using a handheld glucose reader (Accu-Chek Compact Plus blood glucose meter; Roche Diagnostics) that had been previously validated for use on fish (Stoot et al. 2014). Blood samples were then centrifuged at 2000g for five minutes (Fisher Scientific Mini Centrifuge) and the resulting plasma was pipetted into two separate $1.5 \mathrm{~mL}$ screw cap vials. Vials were kept in liquid nitrogen until they could be transferred to a $-80^{\circ} \mathrm{C}$ freezer where they remained until cortisol analysis could be done. 


\subsubsection{Conspecific Density Experiment}

This study was also performed at the Queen's University Biological Station from July 3 through July 6, 2014. Pumpkinseed were collected using angling from Lake Opinicon from both limnetic $(n=51)$ and littoral $(n=50)$ locations as noted above. Surface water temperature throughout the four day period remained fairly constant $\left(25-27^{\circ} \mathrm{C}\right)$. Protocol was identical to the habitat complexity experiment in terms of blood sampling and sample processing aside from the fact that habitat was standardized and only fish density was manipulated. Bins were left empty of substrate and vegetation and filled up to $30 \mathrm{~cm}$ with lake water. The three treatments included bins with either no conspecifics, one conspecific, or five conspecifics that varied in size between 125 and $218 \mathrm{~mm}$. Fish were again assigned treatments and left for 42 minutes as in the habitat manipulation. Baseline and maximum samples were collected as above.

\subsubsection{Cortisol Assays}

Baseline and maximum plasma cortisol levels were assessed using a commercial radioimmunoassay kit (RIA, MP Biomedicals, Santa Ana, California, USA) and subsequently read with a 2480 WIZARD automatic gamma counter (PerkinElmer, Waltham, Massachusetts, USA) following the methods outlined by Gamperl et al. (1994). The intra- and inter-assay coefficients of variation were $8 \%$ and $10 \%$, respectively.

\subsubsection{Statistical Analysis}

Stress responsiveness (for glucose and cortisol) was determined by subtracting the baseline value from the maximum value achieved after the 45 minute experiment. A two-way analysis of variance (ANOVA) was used to test if baseline glucose, maximum glucose, glucose responsiveness, baseline cortisol, maximum cortisol, and cortisol responsiveness differed significantly between fish collected at the littoral and limnetic sites. Baseline, maximum and 
responsiveness of both glucose and cortisol represented the dependent variables and treatment type (the four levels of habitat complexity or the three levels of fish density) and collection site (i.e. littoral versus limnetic) were the two independent variables. A Shapiro-Wilk's test was used to ensure normality assumptions were satisfied prior to performing the ANOVA. When not met, square-root and log transformations were utilized in an attempt to normalize the data. Statistical

analyses were performed using $\mathrm{R}$ version 3.1.2. Significance level was set a priori as 0.05 for all tests performed.

\subsection{Results}

A total of 117 and 101 pumpkinseed were collected and had two blood samples successfully collected within the parameters of the study (i.e., $<3 \mathrm{~min}$ for baseline) for the habitat and conspecific manipulations, respectively.

\subsubsection{Habitat Complexity Experiment}

Fish used in the experiments were of similar total length across treatments (Table 2.1; grand mean of $192 \pm 22 \mathrm{~mm})$.

Baseline glucose levels were similar across sampling sites and among the four experimental habitat types with no interaction effect observed (Table 2.1; Figure 2.1). Maximum glucose levels were similar among the four experimental habitat types and no interaction effect was observed (Table 2.1; Figure 2.1). However, maximum glucose levels did differ significantly between sampling sites with fish from the littoral site having higher elevated glucose levels than fish from the limnetic site (Table 2.1; Figure 2.1). Glucose responsiveness was similar among the four experimental habitat types and no interaction effect was observed (Table 2.1; Figure 
2.1). Sampling site did have a significant effect on glucose responsiveness with fish from the littoral site having higher glucose responsiveness than fish from the limnetic site (Table 2.1; Figure 2.1).

Baseline cortisol levels were similar across sampling sites and among the four experimental habitat types with no interaction effect observed (Table 2.1; Figure 2.2). Maximum cortisol levels were similar across the four experimental habitat types and no interaction effect was observed (Table 2.1; Figure 2.2). However, maximum cortisol levels did differ significantly between sampling sites with fish from the littoral site having higher elevated cortisol levels than fish from the limnetic site (Table 2.1; Figure 2.2). Cortisol responsiveness was similar among the four experimental habitat types and no interaction effect was observed (Table 2.1; Figure 2.2). There was a trend, though non-significant, demonstrating that fish from the littoral site tended to have higher cortisol responsiveness than fish from the limnetic site (Table 2.1; Figure 2.2).

\subsubsection{Conspecific Density Experiment}

Fish used in the experiment were of similar total length across treatments (Table 2.2; grand mean of $190 \pm 20 \mathrm{~mm})$.

Baseline glucose levels were similar across sampling sites and among the three conspecific groups with no interaction effect observed (Table 2.2; Figure 2.3). Maximum glucose levels were similar across sampling sites and among the three conspecific groups with no interaction effect observed (Table 2.2; Figure 2.3). Glucose responsiveness was similar across sampling sites and among the three conspecific groups with no interaction effect observed (Table 2.2; Figure 2.3). 
Baseline cortisol levels were similar across sampling sites (Table 2.2; Figure 2.4). The three conspecific groups had a near-significant effect on baseline cortisol and a near-significant interaction effect was also observed (Table 2.2; Figure 2.4). Maximum cortisol levels were similar across sampling sites and among the three conspecific groups (Table 2.2; Figure 2.4). Cortisol responsiveness was similar across sampling sites and among the three conspecific groups with no interaction effect observed (Table 2.2; Figure 2.4).

\subsection{Discussion}

This study tested the hypothesis that habitat complexity and conspecific density can result in changes in baseline GC levels and GC responsiveness with patterns varying dependent upon whether fish were sourced from littoral or limnetic habitats. Using pumpkinseed, which are known to display trophic dimorphism (Gillespie and Fox 2003), we subjected fish from both sampling sites (i.e. littoral vs limnetic) to treatments varying in habitat complexity and conspecific density. It was hypothesized that pumpkinseed from littoral sites exhibit lower GC responsiveness when exposed to higher habitat complexity and higher conspecific density as these are conditions that littoral pumpkinseed are most familiar with (Warren 2009). For similar reasons it was hypothesized that pumpkinseed from limnetic sites exhibit lower GC responsiveness with lower habitat complexity and lower conspecific density. Overall, habitat complexity and conspecific density treatments did not have a significant effect on baseline and maximum glucose or cortisol concentrations nor responsiveness. In the habitat experiment, the fish collected from the littoral site did have significantly higher $(\mathrm{P}<0.05)$ concentrations of maximum glucose, glucose responsiveness, and maximum cortisol and a nearly significantly 
$(\mathrm{P}<0.1)$ higher cortisol responsiveness than the limnetic fish. In addition, in the conspecific density experiment there was a near-significant interaction effect $(\mathrm{P}<0.1)$ between sampling site and treatment on baseline cortisol.

\subsubsection{Habitat Complexity Experiment}

Baseline levels of glucose and cortisol did not differ significantly between fish sourced from littoral and limnetic environments, indicating that the GC levels required for basic maintenance and survival in the species may be similar between the two. However, the maximum glucose and cortisol levels and glucose responsiveness reached were significantly different between fish sourced from the two environments and there was also a trend towards a significant difference in cortisol responsiveness between the two environments. This suggests that the fish sourced from the two environments may have different physiological responses to challenges, despite the environment experienced post-stressor. Red and black head colour morphs of Gouldian finches (Erythrura gouldiae) exhibited differences in GC levels following a nutritional stressor (Pryke et al. 2012). Black morphs had increased free corticosterone levels while red morphs showed a decrease following the stressor (Pryke et al. 2012). Species that demonstrate within-sex variation, such as males with different reproductive tactics, can also display different physiological characteristics. Bluegill exhibit three separate male morphs separated by reproductive strategy (i.e. parental and two cuckolder morphs) and the cuckolder morphs had higher baseline cortisol levels than the parental morph (Knapp and Neff 2007). The habitat complexity treatments had no significant effect on the cortisol or glucose levels even though it was predicted that fish would have a lower stress response when placed in an environment that was familiar. An individual living in an optimal habitat has been shown to better respond (i.e. rapid increase in GCs with a quick return to a low baseline GC concentration) 
to a challenge than those living in degraded habitats (Wingfield 2005; Breuner et al. 2008;

Bonier et al. 2009a; Bush and Hayward 2009). However, habitat quality is a subjective matter and one habitat that may be perceived as ideal by one individual may be less than ideal to another between species or even between different morphs of a single species.

\subsubsection{Conspecific Density Experiment}

It was hypothesized that pumpkinseed from littoral sites are most accustomed to higher fish densities while those from limnetic sites are most accustomed to lower fish densities and that both variants exhibit lower GC responsiveness when exposed to conditions familiar to them following a standardized stressor. It was found that conspecific density had no significant effect on baseline, elevated, or responsiveness for glucose and cortisol. As well, unlike the habitat complexity experiments, no significant difference between sampling site was seen for our measured values. The only near-significant result $(0.05<\mathrm{P}<0.1)$ observed was an interaction effect between sampling site and conspecific density on baseline cortisol concentrations.

Similar to the habitat complexity experiments, baseline levels of glucose and cortisol did not differ significantly across treatments or between littoral and limnetic morphs. This supports the idea that the levels required for survival and maintenance are similar between the littoral and limnetic morphs though no studies to test this have been done to our knowledge. In contrast to the habitat complexity experiments, elevated levels of glucose and cortisol, and consequently responsiveness for both, were not significantly different between littoral and limnetic fish. In lake sturgeon (Acipenser fulvescens) the presence of other conspecifics similarly did not have an effect on maximum cortisol levels though it did shorten the stress response overall (Allen et al. 2009). The duration of the stress response was not assessed in this study, so whether this also occurs in pumpkinseed is not known. Free-living spotted salamanders (Ambystoma maculatum) 
showed similar results in that those breeding in areas of higher conspecific densities showed no significant differences in baseline cortisol concentrations (Cooperman et al. 2004). In contrast, North American red squirrel (Tamiasciurus hudsonicus) females exposed to high density cues (i.e. playbacks of conspecific vocalizations) exhibited higher levels of elevated GCs which, in turn, affected their offspring (Dantzer et al. 2013). As reviewed by Hawkley and colleagues (2012), social isolation in gregarious species can be associated with an increase, decrease, or no change of baseline GC levels making it a highly context-dependent factor.

\subsubsection{Synthesis and Conclusions}

Though no significant effect of habitat complexity or conspecific density was seen in this study it was observed, at least in the habitat experiments, that littoral and limnetic pumpkinseed may exhibit different physiological responses to stressors. This study did have its limitations. Reproductive status can alter GC concentrations (e.g. Gesquiere et al. 2008) as reproduction itself can act as a stressor (Bonier et al. 2009b). Our study took place from the end of June to early July in 2014. Though spawning in pumpkinseed sunfish usually occurs from early May to August (Warren 2009), it has been reported that the spawning season in Lake Opinicon ends for the vast majority of pumpkinseed by the middle of June (Keast 1980); therefore, reproduction should have been avoided though fish were not examined for signs of spawning activity in this study. Another factor known to influence the GC response is sex (e.g. Lance et al. 2001). Pumpkinseed sex is not readily visible without lethal sampling, so fish were not sexed in this study. This study was also based on the assumption that littoral and limnetic pumpkinseed display polymorphism and this manifests itself in measurable physical differences. The trophic dimorphism in pumpkinseed is most easily distinguished by molar size and gill raker spacing (Gillespie and Fox 2003). Fish in this study were unharmed and returned to the lake when their 
trial was complete and as a result no measurements could be taken to validate this dimorphism in Lake Opinicon. As well, a study by Robinson and colleagues (1993) reported that this morphological dimorphism may only be present in the absence of competitors, such as bluegill sunfish, which are in great abundance in Lake Opinicon. Time of day (e.g. Cousineau et al. 2014) and seasonality (e.g. Wingfield et al. 1992) are both capable of influencing the stress response. The studies were performed over a 10 day period with the habitat quality experiment taking place on the first six days and the conspecific density experiment taking place on the last three days, so it is unlikely seasonality would have had a major influence on this study. However, the proximity to the reproductive period could potentially lead to significant temporal (seasonal) changes across the period that we conducted the study.

With growing human disturbance affecting aquatic habitats around the globe (e.g., Dudgeon et al. 2006), understanding how alterations in habitat features and density of conspecifics influence baseline and stress-induced GCs is important (Angelier and Wingfield 2013). Although we did not detect any strong evidence of habitat or density-specific effects on baseline GCs or GC responsiveness, additional testing on species that are regarded as more habitat specialists seems warranted. Moreover, experimental approaches where animals are held in tanks or mesocosms with specific habitat features or densities and then altering them to identify if there are changes in GCs would be useful. 


\subsection{Tables}

Table 2.1: Results of a two-way ANOVA with habitat type, capture site and the interaction as the independent variables and baseline, elevated and response levels of both cortisol and glucose as the targeted dependent variables. Comparing stress level proxies of pumpkinseed fish (Lepomis gibbosus) captured from littoral and limnetic sites on Lake Opinicon (Ontario, Canada) prior to and following a standardized air stressor. Significant values $(\mathrm{P}<0.05)$ are shown in bolditalics, near-significant values $(0.05<\mathrm{P}<0.1)$ are shown in italics.

\begin{tabular}{|c|c|c|c|c|c|c|c|c|c|}
\hline & \multicolumn{3}{|c|}{ Habitat Type } & \multicolumn{3}{c|}{ Capture Site } & \multicolumn{3}{c|}{ Habitat type X Capture } \\
Site
\end{tabular}


Table 2.2: Results of a two-way ANOVA with conspecific, capture site and the interaction as the independent variables and baseline, elevated and response levels of both cortisol and glucose as the targeted dependent variables. Comparing stress level proxies of pumpkinseed fish (Lepomis gibbosus) captured from littoral and limnetic sites on Lake Opinicon (Ontario, Canada) prior to and following a standardized air stressor. Near-significant values $(0.05<\mathrm{P}<0.1)$ are shown in italics.

\begin{tabular}{|c|c|c|c|c|c|c|c|c|c|}
\hline & \multicolumn{3}{|c|}{ Conspecific Group } & \multicolumn{3}{c|}{ Capture Site } & \multicolumn{3}{c|}{ Habitat type X Capture } \\
Site
\end{tabular}




\subsection{Figures}
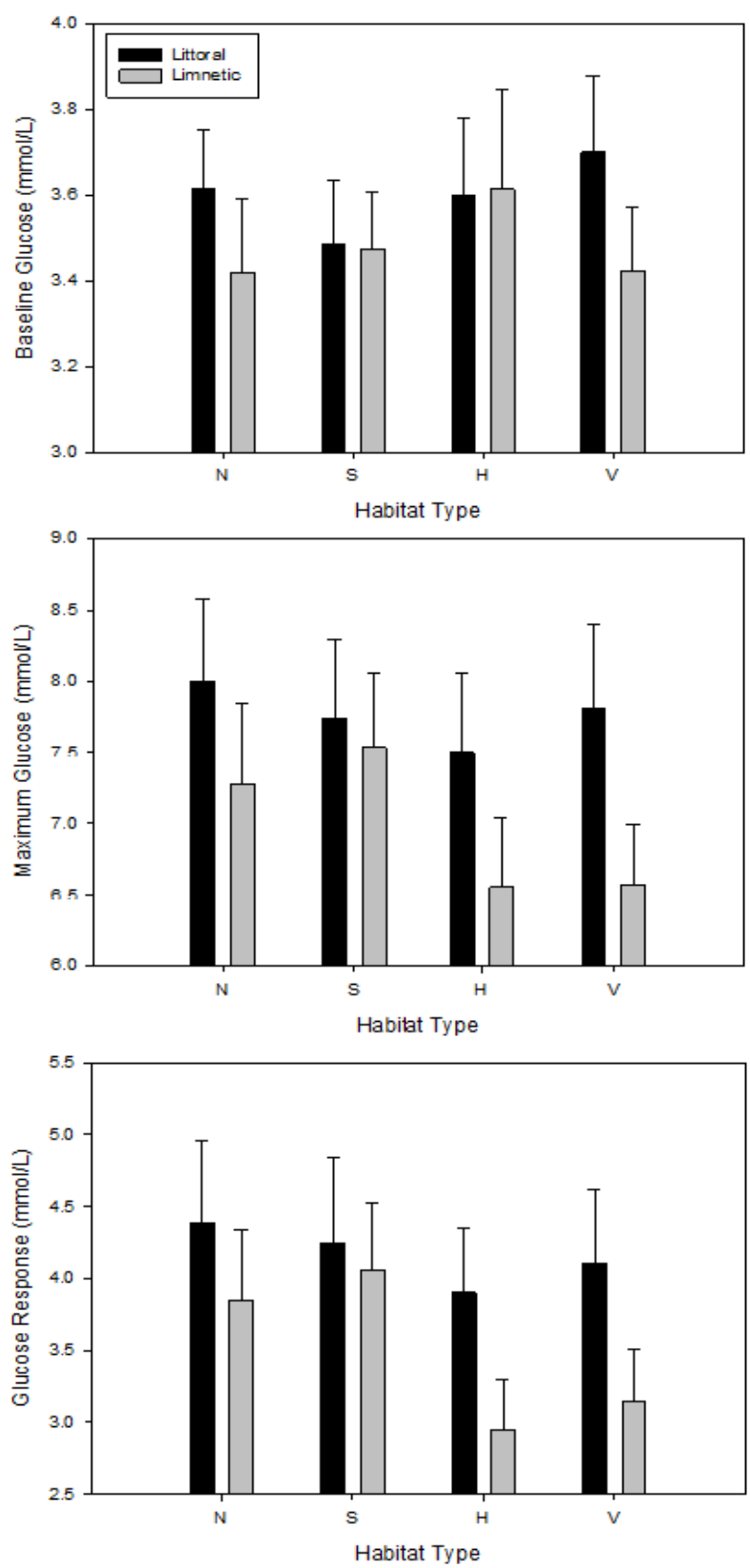

Figure 2.1: Baseline and elevated glucose levels and glucose responsiveness $(\mathrm{mmol} / \mathrm{L})$ for pumpkinseed sunfish collected from littoral and limnetic sites and assigned to four experimental habitat treatments (only water $(\mathrm{N})$, cobble substrate $(\mathrm{S})$, cobble substrate with $50 \%$ vegetative cover $(\mathrm{H})$, and cobble substrate with $90 \%$ vegetative cover $(\mathrm{V}))$. Data presented are means \pm 1 standard error; $\mathrm{n}=62$ and 55 for limnetic and littoral sites, respectively. 

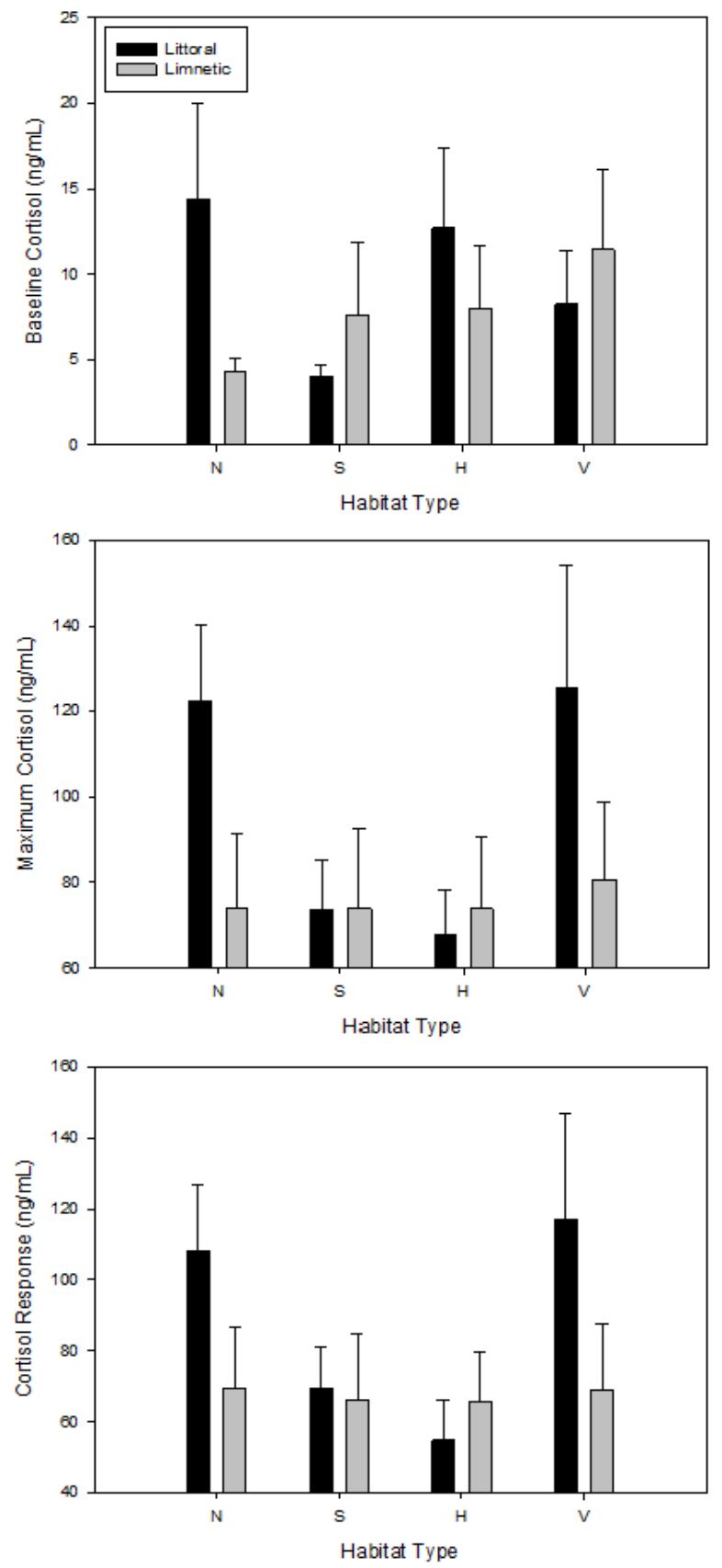

Figure 2.2: Baseline and elevated cortisol levels and cortisol responsiveness $(\mathrm{ng} / \mathrm{mL})$ for pumpkinseed sunfish collected from littoral and limnetic sites and assigned to four experimental habitat treatments (only water $(\mathrm{N})$, cobble substrate $(\mathrm{S})$, cobble substrate with $50 \%$ vegetative cover $(\mathrm{H})$, and cobble substrate with $90 \%$ vegetative cover(V)). Data presented are means \pm 1 standard error; $\mathrm{n}=62$ and 55 for limnetic and littoral sites, respectively. 

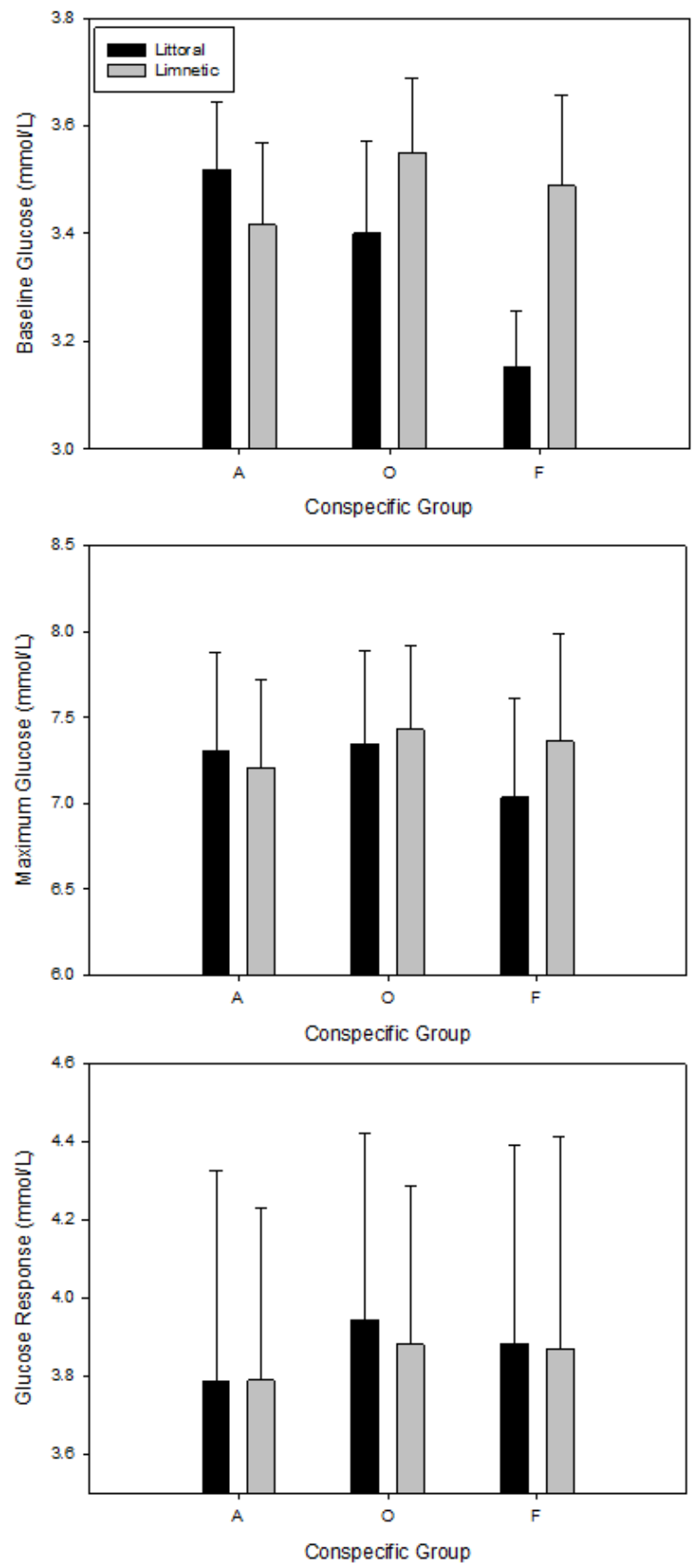

Figure 2.3: Baseline and elevated glucose levels and glucose responsiveness (mmol/L) for pumpkinseed sunfish collected from littoral and limnetic sites and assigned to three experimental conspecific treatments (no other conspecifics $(\mathrm{A})$, one other conspecific $(\mathrm{O})$, and five other conspecifics (F)). Data presented are means \pm 1 standard error; $\mathrm{n}=51$ and 50 for limnetic and littoral sites, respectively. 

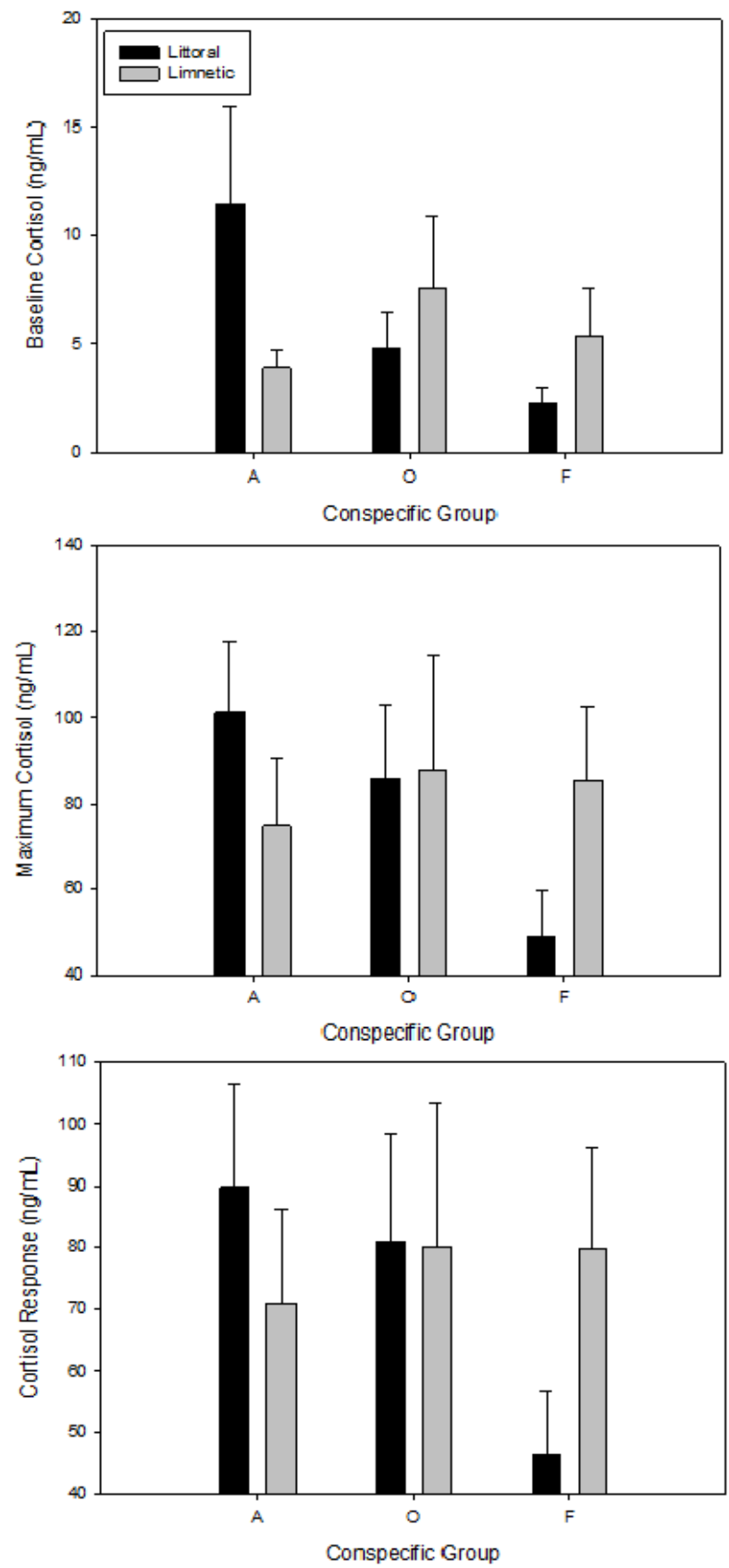

Figure 2.4: Baseline and elevated cortisol levels and cortisol responsiveness $(\mathrm{ng} / \mathrm{mL})$ for pumpkinseed sunfish collected from littoral and limnetic sites and assigned to three conspecific treatments (no other conspecifics (A), one other conspecific (O), and five other conspecifics (F)). Data presented are means \pm 1 standard error; $n=51$ and 50 for limnetic and littoral sites, respectively. 


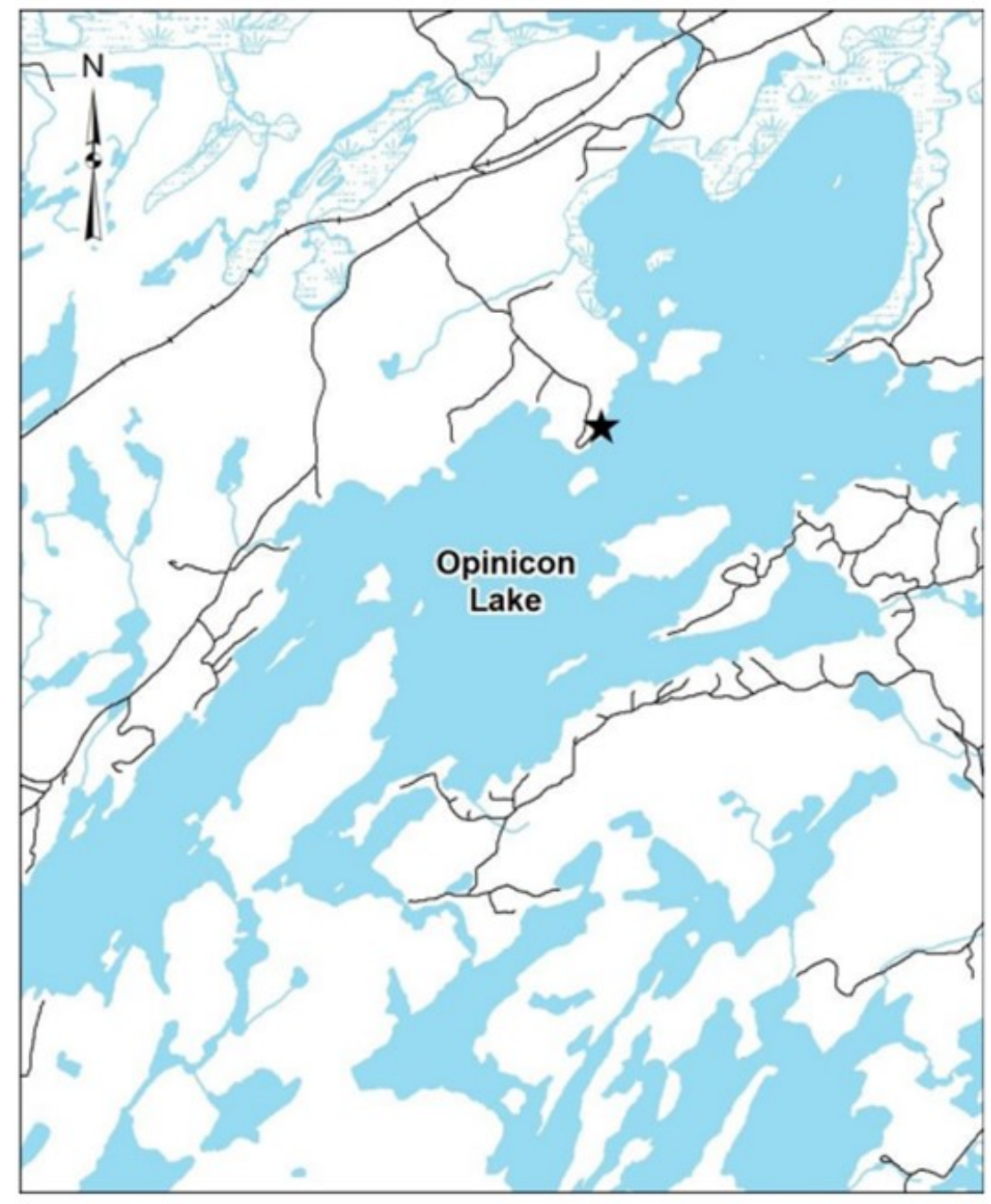

Figure 2.5: Lake Opinicon $\left(44^{\circ} 56^{\prime} \mathrm{N}, 76^{\circ} 33^{\prime} \mathrm{W}\right)$ in Ontario, Canada where this study took place. The entire lake was utilized for angling of pumpkinseed and the star denotes the location of Queen’s University Biology Station. Taken from Pullen (2013). 


\section{Chapter 3: Seasonal Variation in Baseline and Maximum Whole-Body Glucocorticoid Concentrations in a Small-Bodied Stream Fish Independent of Habitat Quality}

\subsection{Abstract}

Alterations to natural habitats and extreme weather events are becoming more intense and frequent due to changes in anthropogenic land use and it is of increasing interest to see how wild animals adapt and respond to changing environmental stressors. The glucocorticoid (GC) stress response permits animals to react appropriately to challenges in the environment but can be affected by many factors, two of which are time of year and habitat quality. This study tested whether baseline and maximum cortisol concentrations varied in relation to habitat quality and season using wild central mudminnows (Umbra limi) collected in each of the four seasons from two connected streams differing in habitat quality. Overall, baseline and maximum cortisol levels did not differ significantly between the two systems varying in habitat quality but baseline cortisol levels in the fall and summer were significantly $(\mathrm{P}<0.01)$ lower than those in winter and spring and maximum cortisol levels in the summer were significantly lower $(\mathrm{P}<0.01)$ than those in the spring. Our results indicate that habitat quality is a complex factor and, at least in this species, does not impact the stress response. In contrast, time of year does impact the stress response in this species and should be considered in the interpretation of stress response data. 


\subsection{Introduction}

Human activities, past and present, have had dramatic changes on the biosphere (Vitousek et al. 1997). As the world's population continues to grow and human development accelerates, natural habitats and weather patterns can become severely altered. Given the direct relationship between habitat quality and organismal health and condition (Huey 1991), degraded habitats can result in alterations to organismal physiology (Wingfield 2005), which has the potential to influence population-level processes (Calow and Forbes 1998; Ricklefs and Wikelski 2002; Fefferman and Romero 2013). Recent studies have begun to unravel some of the specific mechanisms by which changes in habitat quality influence resident biota (Wikelski and Cooke 2006; Cooke et al. 2013). Measuring glucocorticoid (GC) levels is one way we are able to begin quantifying the effects of human activities, such as habitat degradation on vertebrates (Homyack

2010; Baker et al. 2013), thus serving as a useful indicator of ecosystem health (Dale and Beyeler 2001).

GCs are found in all vertebrates and changes in GC levels play an important role in responding to environmental challenges (Sapolsky et al. 2000). GCs are secreted by as a result of activation of the hypothalamic-pituitary-adrenal (HPA) axis in reptiles, birds, and mammals and the hypothalamic-pituitary-interrenal (HPI) axis in fishes and amphibians (Bonga, 1997; Reeder and Kramer 2005). This axis is activated when an organism experiences an actual or perceived stressor in the environment (Sapolsky et al. 2000). The acute stress response is widely considered to be beneficial to an organism as it is seen across all vertebrates and assists in reacting appropriately to potentially lethal encounters (Breuner et al. 2008; Wingfield et al. 1998). However, it is also accepted that long-term elevation of GCs can be severely detrimental 
to the health, reproduction, and survival of an organism (Breuner et al. 2008). Baseline GC levels are considered to regulate basic survival needs (e.g. feeding behaviour, locomotor activity and metabolism [Landys et al. 2006]) and maximum GC levels are those that can be measured following the physiological response to a challenge or acute stressor (Sapolsky et al. 2000). Baseline samples are often collected immediately following capture (typically within 3 minutes [Romero and Reed 2005]) and then a stress-induced maximal value is measured some period thereafter following exposure to a standardized stressor (e.g. timed handling stressor or air stressor in fish). It is generally considered that lower baseline GC levels indicate an individual or population that is in better condition or exposed to less stress than those with higher baseline GC levels (Bonier et al. 2009a; Busch and Hayward 2009). As mentioned previously, an acute stress response is beneficial to an organism, though one that incites a quick increase of GCs followed by a rapid decrease back to baseline GC levels would intuitively serve the organism better, allowing them to respond appropriately to a threat but return to normal functioning quickly, thus avoiding the consequences of chronic stress (Breuner et al. 2008; Angelier and Wingfield 2013).

Researchers over the past several decades have started to explore the effects of habitat quality on baseline and stress-induced GCs, particularly among mammals, birds, and herpetofauna. However, the results have been inconclusive and indicate context specificity. Quantifying habitat quality in a stream environment can include measurements of factors such as macroinvertebrate and fish population levels as well as changes in flow rate, nutrient and contaminant concentrations, and channel morphology (Meyer et al. 2005). In spotted salamanders (Ambystoma maculatum), for example, female baseline GC levels were not significantly different between a disturbed and undisturbed site but maximum GC levels were 
significantly higher in those from the undisturbed site (Newcomb Homan et al. 2003). In male spotted salamanders, the undisturbed site showed significantly higher baseline and maximum GC levels than the disturbed site (Newcomb Homan et al. 2003). Hopkins and DuRant (2011) evaluated baseline and maximum GCs of eastern hellbenders (Cryptobranchus alleganiensis) from two stream reaches with differing habitat quality and found no habitat-related differences in GC levels. In the small rodent, the degu (Octodon degus), habitats with good cover quality, low ectoparasite loads, and increased food availability were associated with lower baseline and maximum GCs (Bauer et al. 2013). Marra and Holberton (1998) studied baseline and maximal GCs in American redstarts (Setophaga ruticilla) from two different habitat types and identified differences in GCs in some, but not all, seasons emphasizing the context-specificity of results. Indeed, interpreting GC results in wild animals is a complex process (Johnstone et al. 2012; Dantzer et al. 2014; Crossin et al., In Press). Interestingly, there are relatively few studies that have examined the influence of habitat quality on wild fish, nor done so among seasons.

The objective of this study was to determine how habitat quality and season correlated with baseline and maximal GC levels in a small-bodied freshwater fish. The model species in this study was central mudminnow (Umbra limi) collected from Watts Creek and Kizell Municipal Drain in Kanata, Ontario, Canada. Central mudminnow (family: Umbridae) are commonly found in freshwater streams, lakes, and ponds of central and eastern North America (Scott and Crossman 1973). Their diet is dependent on their life-history stage but is typically quite varied, consisting of insect larvae and small crustaceans (Peckham and Dineen 1957; Martin-Bergmann and Gee 1985). Central mudminnow are typically found in areas with low current and high vegetative cover (Peckham and Dineen 1957; Martin-Bergmann and Gee 1985). The two sampling locations in this study join at a confluence and sampling was done $150 \mathrm{~m}$ 
upstream of this confluence in both streams. Previous studies in this area demonstrated that this species travels very little between the two adjoining streams (Bliss et al. 2015). This particular combination of movement and location permitted testing of how habitat quality plays a role in subsequent responses to a standardized stressor while controlling for factors such as weather events, temperature, etc. Habitat quality is a complex idea but in this context Kizell Drain was considered to be the more degraded system due to lower levels of sinuosity, habitat complexity, cover, and types of sediment (Goldstein and Meador 2005; Walsh et al. 2005; Bliss et al. 2015). Although recent advances in techniques allow collection of small sample volumes to estimate plasma GC levels (Sheriff et al. 2011), it is not possible to obtain a sufficiently large blood sample volume for a cortisol assay from small organisms such as the central mudminnow, so a whole-body cortisol measure was conducted (Feist and Schreck 1990; de Jesus et al. 1991). Given that multiple samples (i.e. baseline and maximum) could not be collected from the same individual, it is not possible to measure individual responsiveness per se but much information can still be obtained from the available whole body samples. The work is based on the hypothesis that organisms in degraded habitats, presumably in poorer condition, have been shown to display increased baseline GC levels (Bonier et al. 2009a) and a depressed response when exposed to a standardized stressor (i.e. Hontela et al. 1992; Norris et al. 1999). This experiment tested the hypothesis that the central mudminnow population collected from Kizell Municipal Drain, a more disturbed stream (Bliss et al. 2015), would display higher baseline GC levels and lower maximum GC levels than the population collected from Watts Creek, a relatively less disturbed stream. 


\subsection{Methods}

\subsubsection{Study Area}

Watts Creek and Kizell Municipal Drain (45²0’42”N, 7552’19’W) are located in Kanata, a suburb of Ottawa, Ontario, Canada. Watts Creek is a tributary of the Ottawa River and collects stormwater from surrounding residential areas, including the aforementioned Kizell Drain. All collections took place at minimum $150 \mathrm{~m}$ upstream from the confluence where Watts Creek and Kizell Drain connect to avoid any possible fish movement. Kizell Drain is narrower, shallower, more channelized, and shows lower habitat complexity and cover than Watts Creek (Bliss et al. 2015). For these reasons, as in previous studies (e.g. Bliss et al. 2015), Kizell is considered a more degraded stream when compared to Watts Creek.

\subsubsection{Fish Sampling}

Fish for this study were collected on October 24 (fall) and December 2 (winter) of 2013, and May 20 (spring) and July 14 (summer) of 2014. Twenty fish were sampled during each collection from both Kizell Municipal Drain and Watts Creek except for the winter sampling for which only 19 fish were sampled from both Kizell and Watts. Backpack electrofishing (Model 12, Smith-Root, Vancouver, W, USA) was used for all sampling events. Electroshocking has been shown to have no direct link to mortality or skeletal damage (except for at extreme conditions) and has been indicated as an acceptable procedure to use for field samplings (Mitton and McDonald 1994). The crew worked upstream and ceased shocking upon netting of a central mudminnow greater than $35 \mathrm{~mm}$. Shocking commenced again at least $2 \mathrm{~m}$ upstream of the last capture location to reduce the likelihood of sampling fish that had already experienced a shock. For both Kizell Drain and Watts Creek, 10 fish were stunned using a cerebral percussion (e.g. 
Chomyshyn et al. 2011) immediately after capture and then stored in liquid nitrogen within three minutes (representing baseline cortisol levels). Meanwhile, the other 10 fish were exposed to a three minute standardized air stressor in a dampened bucket followed by 27 minutes in $5 \mathrm{~cm}$ of water. Using an air stressor, which typically involves leaving the fish in a moistened container without water for a short period of a time, is a common method used among fish studies to elicit the stress response. After $30 \mathrm{~min}$ in the dampened bucket these fish were stunned as above and stored in liquid nitrogen (representing maximum cortisol). As fish were sampled, they were

alternatively assigned to either baseline or maximum groups. All samples were stored in a $-80^{\circ} \mathrm{C}$ freezer until cortisol analysis could be done.

\subsubsection{Cortisol Analysis}

Whole frozen fish were crushed using a mortar and pestle and liquid nitrogen to keep the samples frozen resulting in a powdery extract. Total lipid extraction was performed using the Folch method (Folch et al. 1957) optimized for central mudminnow. First, $30 \mathrm{~mL}$ of Folch solution ( 2 chloroform: 1 methanol $\mathrm{v} / \mathrm{v}$ ) was added and the mixture homogenized (Polytron homogenizer; Kinematica, Luzern, Switzerland) for two minutes. After sitting for 20 mins, 10 $\mathrm{mL}$ of $\mathrm{KCl}$ with $5 \mathrm{mM}$ EDTA was added and the extract allowed to settle for another 20 mins. The lipid fraction was removed using a pipette and transferred to a test tube. The solvent was then evaporated under a liquid nitrogen stream in a fumehood. The lipids were finally resuspended in $30 \mu \mathrm{L}$ of ethylene glycol monomethyl ether (EGME) and stored until the cortisol assay was performed. When all lipid extractions were complete, whole-body cortisol concentration was further measured using a commercial radioimmunoassay kit (RIA, MP Biomedicals, USA) and subsequently read with a 2480 WIZARD automatic gamma counter 
(PerkinElmer, Waltham, Massachusetts, USA). The intra- and inter-assay coefficients of variation were $8 \%$ and $10 \%$, respectively.

\subsubsection{Statistical Analysis}

A two-way analysis of variance (ANOVA) was used to test if baseline cortisol and maximum cortisol differed significantly between fish collected from Watts Creek and Kizell Drain over winter, spring, summer, and fall. Baseline cortisol and maximum cortisol represented the dependent variables and season and collection site (i.e. Watts Creek versus Kizell Drain) were the two independent variables. A Shapiro-Wilk's test was used to ensure normality assumptions were satisfied prior to performing the ANOVA. When not met, square-root and log transformations were utilized in an attempt to normalize the data. Statistical analyses were performed using R version 3.1.2. When significant, a Tukey HSD test was used to determine which factors differed in baseline and maximum cortisol levels. Significance levels were set $a$ priori as 0.05 for all tests performed and results are presented as mean \pm standard deviation.

\subsection{Results}

Central mudminnow collected from Watts Creek and Kizell Drain did not differ statistically in mass, total length, or condition factor (Table 3.1), although all three measurements did differ significantly $(\mathrm{P}<0.05)$ across seasons and a significant $(\mathrm{P}<0.05)$ interaction effect between site and season was present for fish mass. Baseline cortisol levels were similar between fish collected from Watts creek and Kizell drain (Table 3.1; Figure 3.1) but differed significantly across seasons (Table 3.1; Figure 3.1) with no significant interaction effect. Baseline cortisol concentrations sampled in the winter and spring were significantly $(\mathrm{P}<0.01)$ greater than the fall 
and summer samples (Table 3.1; Figure 3.1). Similarly, maximum cortisol levels did not differ between fish collected from Watts and Kizell Drain (Table 3.1; Figure 3.2) but differed significantly $(\mathrm{P}<0.05)$ across seasons (Table 3.1; Figure 3.2). More specifically, maximum cortisol concentrations in the summer samples were significantly $(\mathrm{P}<0.01)$ lower than concentrations observed in the spring samples (Figure 3.2).

\subsection{Discussion}

This study aimed to test the hypothesis that habitat quality influences baseline and maximum GC levels in central mudminnow over the four seasons. Central mudminnow were sampled four times over the course of a year from Kizell drain, deemed a more disturbed habitat, and from Watts creek, deemed a more pristine habitat. As mentioned previously, due to human activity in the area, Kizell Drain displays lower diversity of sediment types and lower levels of sinuosity, habitat complexity, and overhead cover resulting in it being considered more degraded than Watts Creek (Bliss et al. 2015). It was predicted that over the four seasons, organisms in the degraded habitat would presumably be in poorer condition and therefore show increased baseline GC levels (Bonier et al. 2009a) in addition to lower maximum GC levels following a standardized air stressor (i.e. Hontela et al. 1992; Norris et al. 1999). Overall, the sampling site (i.e. habitat quality) did not have a significant effect on either baseline or maximum GC levels. However, there were significant differences seen across the season during which sampling occurred. Winter and spring baseline GC concentrations were significantly higher than the summer and fall concentrations. Spring maximum GC concentrations were significantly higher than the summer concentrations. For both baseline and maximum GC concentrations, the 
highest values were sampled during the spring while the lowest values were sampled during the fall and summer, respectively.

There were no significant differences for either the baseline or maximum GC levels between Watts Creek and Kizell Drain in any of the four seasons. Although few studies have examined the effect of habitat quality on the GC response in fish, freshwater fish are among the species most affected by habitat degradation (Jeffrey et al. In Press). Similar to our findings, Hopkins and DuRant (2011) found that eastern hellbenders (Cryptobranchus alleganiensis) from disturbed and non-disturbed sites displayed no differences in baseline or maximum GC levels or in GC responsiveness in relation to their different habitats. Creek chub (Semotilus atromaculatus) demonstrated an attenuated stress response in fish collected from an agricultural stream (i.e. disturbed) following thermal and hypoxic challenges (Blevins 2012; Blevins et al. 2014) but showed no difference in response to an experimental cortisol injection across varying habitats in a separate study (Nagrodski et al. 2013). Largemouth bass (Micropterus salmoides) collected from streams with lower percentage of wetland areas (i.e. degraded habitat) had increased baseline GC levels and decreased GC responsiveness when compared to those from areas with higher wetland percentage (King 2014). It is clear that the effect of habitat quality on the GC stress response is context dependent and can vary not only between species but also with different measures of habitat quality.

Previous work on Watts Creek and Kizell Drain (i.e. Bliss et al. 2015) indicated that central mudminnow travel between the two reaches but do so rarely. As such, sampling was not conducted within $150 \mathrm{~m}$ of the confluence; however, we cannot exclude the possibility that there was some movement influencing our results. Watts Creek is more sinuous and has higher habitat complexity, substrate diversity, and in stream cover than Kizell Drain resulting in Kizell Drain 
being designated as a degraded habitat (Bliss et al. 2015). Though it seems clear that Kizell Drain has been more anthropogenically influenced, it is still difficult to determine whether a species considers the habitat to be unsuitable. In fact, in the Watts Creek watershed, higher numbers of central mudminnow are found in Kizell Drain compared to Watts Creek (Bliss et al. 2015). In light of the results, it is possible that Kizell Drain provides a suitable habitat for central mudminnow, particularly in the winter when they are found assembled in deeper pools (MartinBergman and Gee 1985). Along Kizell there are a few such pools that would meet the criteria for central mudminnow overwintering requirements (Bliss et al. 2015) and therefore be as desirable a habitat as Watts.

Though no differences were seen between sites, there was a significant difference in both baseline and maximum GC levels between seasons. Baseline and maximum GC levels were highest in the spring, corresponding with the end of the breeding season in central mudminnow (Peckham and Dineen 1957). This study did not examine individual gonad development as the whole body was used for cortisol analysis but breeding in central mudminnows occurs in the early spring (Peckham and Dineen 1957). Wingfield and colleagues (1994) also found the highest observed GC response during the breeding season in common redpolls (Acanthis flammea). These findings correspond to the cort-adaptation hypothesis which predicts a positive relationship between reproductive success and baseline cort under the pretext that reproduction itself can act as a stressor, resulting in increased GC concentrations (Bonier et al. 2009a, 2009b). There have been few studies in fish examining seasonal changes in the stress response. Wingfield and Grimm (1977) observed maximum plasma GC levels during pre-spawning in plaice (Pleuronectes platessa), similar to what we observed in central mudminnow. Other studies report maximum baseline GC levels occur in the winter for Australian snapper (Pagrus 
auratus [Pankhurst and Sharples 1992]) or show no seasonal related differences in black bream (Acanthopagrus butcheri [Haddy and Pankhurst 1999]). More studies need to examine changes in baseline, maximum, and responsiveness for GCs over the seasons in order to determine if there is a general trend in teleost fishes.

High baseline GC levels are frequently attributed to individuals in worse condition (Bonier et al. 2009a). The highest baseline levels in this study were seen in the winter and spring. The higher baseline and maximum cortisol levels during the spring observed in this study could be due to reproduction acting as a stressor even though it will also increase individual fitness (Bonier et al. 2009b). Though fish were not sexed in this study, this increase in GCs around the breeding season has been observed to occur in both sexes (e.g. Wingfield et al. 1994). The higher GC concentrations observed in the winter could also be in response to the winter being more challenging in terms of available food sources, low temperatures, restricted movement, predator avoidance, and ice movements (Brown et al. 1994; Cunjak 1996). Future studies should include the sex of the individuals in order to determine if this significance between seasons differs between males and females. Examining the breeding season for juvenile and reproductive central mudminnow would allow us to observe if it is the stress of reproduction that is causing the higher GC levels during the spring. With global changes and extreme weather events becoming more frequent (Easterling et al. 2010) it is important to understand what a "normal" stress response is for species across seasons in order for us to interpret future studies appropriately. 


\subsection{Tables}

Table 3.1: : Results of a two-way ANOVA with capture site and season as the independent variables and weight, baseline cortisol, and maximum cortisol as the measured dependent variables. Comparing pre- and post-stress response of central mudminnow (Umbra limi) collected from Watts creek and Kizell drain using a standardized air stressor. Significant values $(\mathrm{P}<0.05)$ are shown in bold-italics.

\begin{tabular}{|c|c|c|c|c|c|c|c|c|c|}
\hline & \multicolumn{3}{|c|}{ Capture Site } & \multicolumn{4}{c|}{ Season } & \multicolumn{3}{c|}{ Season X Capture Site } \\
\hline Variable & $\mathrm{F}$ & $\mathrm{df}$ & $\mathrm{P}$ & $\mathrm{F}$ & $\mathrm{df}$ & $\mathrm{P}$ & $\mathrm{F}$ & $\mathrm{df}$ & $\mathrm{P}$ \\
\hline Weight $(\mathrm{g})$ & 0.269 & 1 & 0.605 & 21.489 & 3 & $<\mathbf{0 . 0 0 0 1}$ & 2.810 & 3 & $\mathbf{0 . 0 4 2}$ \\
\hline Length (mm) & 0.441 & 1 & 0.508 & 13.848 & 3 & $<\mathbf{0 . 0 0 0 1}$ & 0.560 & 3 & 0.642 \\
\hline Condition factor $\left(\mathrm{g} / \mathrm{cm}^{3}\right)$ & 0.240 & 1 & 0.625 & 3.330 & 3 & $\mathbf{0 . 0 2 1 3}$ & 2.361 & 3 & 0.0737 \\
\hline Baseline cortisol (ng/g) & 0.751 & 1 & 0.389 & 8.434 & 3 & $<\mathbf{0 . 0 0 0 1}$ & 0.960 & 3 & 0.416 \\
\hline $\begin{array}{c}\text { Maximum cortisol } \\
\text { (ng/g) }\end{array}$ & 1.568 & 1 & 0.215 & 4.169 & 3 & $\mathbf{0 . 0 0 9}$ & 1.614 & 3 & 0.194 \\
\hline
\end{tabular}




\subsection{Figures}

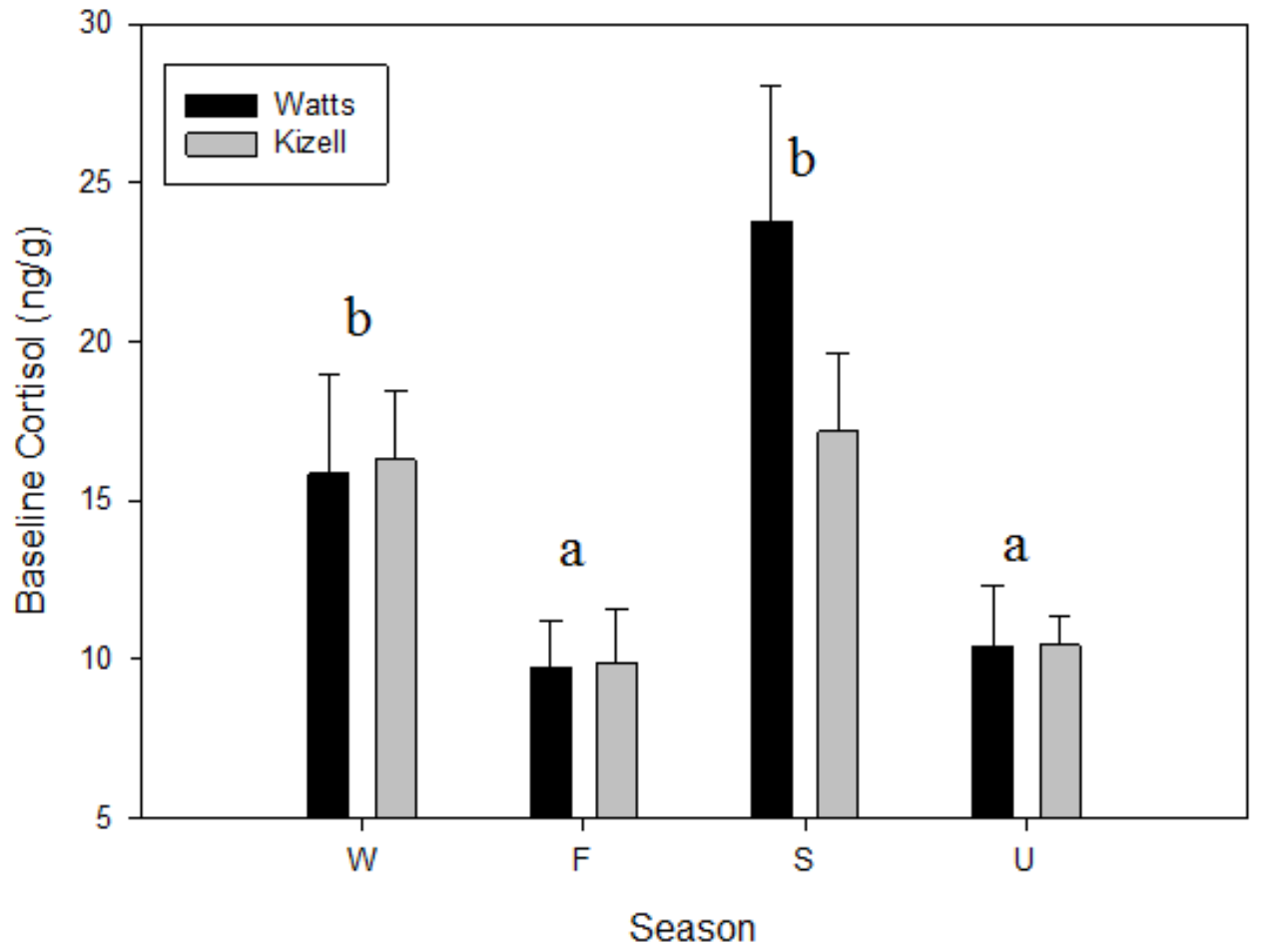

Figure 3.1: Baseline cortisol (ng/g) for central mudminnow collected from Watts creek and Kizell drain over four seasons (winter, W; fall, F; spring, S; summer, U). Winter and summer baseline cortisol values differed significantly $(\mathrm{P}<0.01)$ from the fall and spring months. Data presented are means \pm 1 standard error; $n=10$ for Watts and Kizell in each of the seasons. 


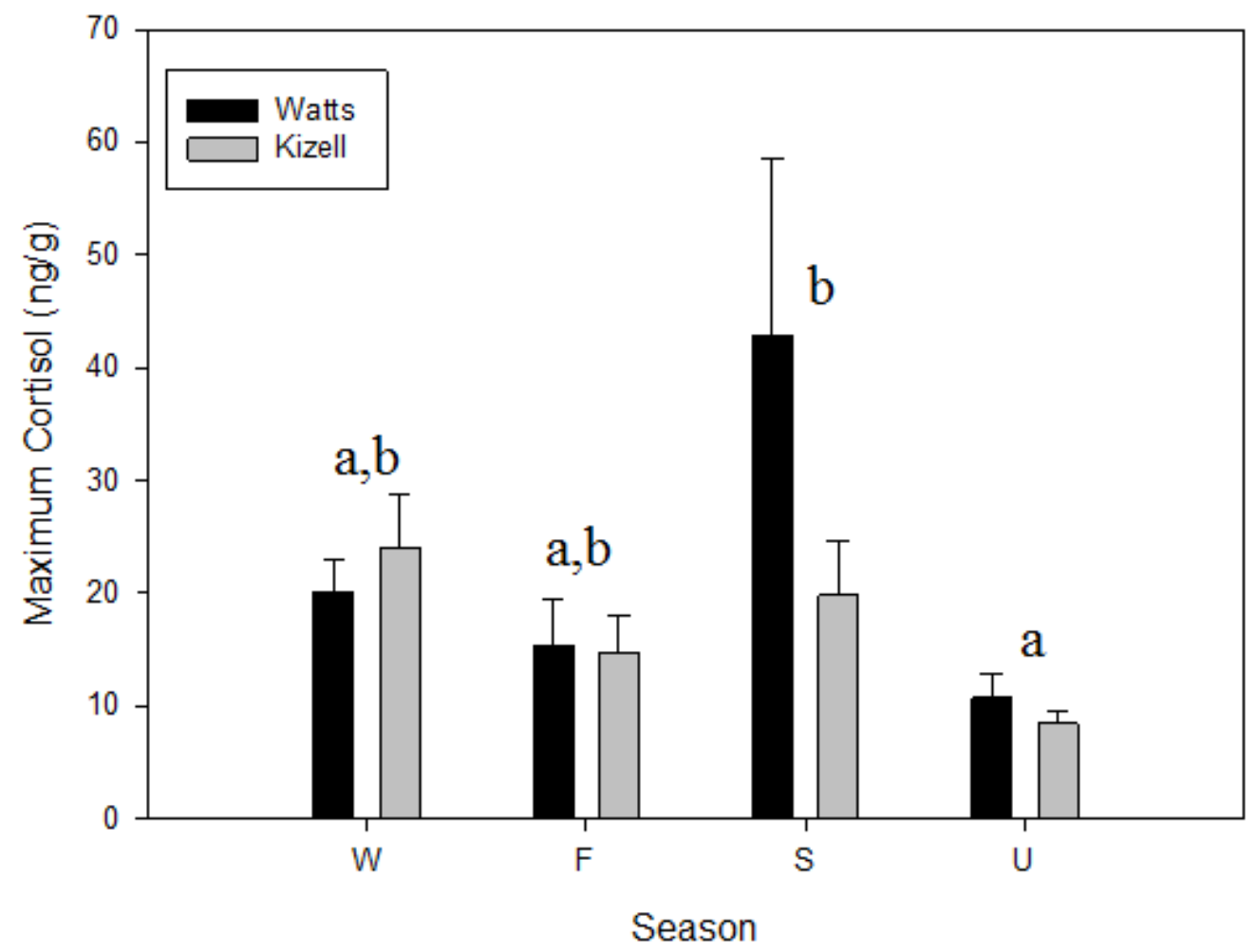

Figure 3.2: Maximum cortisol (ng/g) for central mudminnow collected from Watts creek and Kizell drain over four seasons (winter, W; fall, F; spring, S; summer, U). Summer maximum cortisol levels differed significantly $(\mathrm{P}<0.01)$ from spring levels. Data presented are means \pm 1 standard error; $\mathrm{n}=10$ for Watts and Kizell in fall spring and summer, $\mathrm{n}=9$ for Watts and Kizell in winter. 


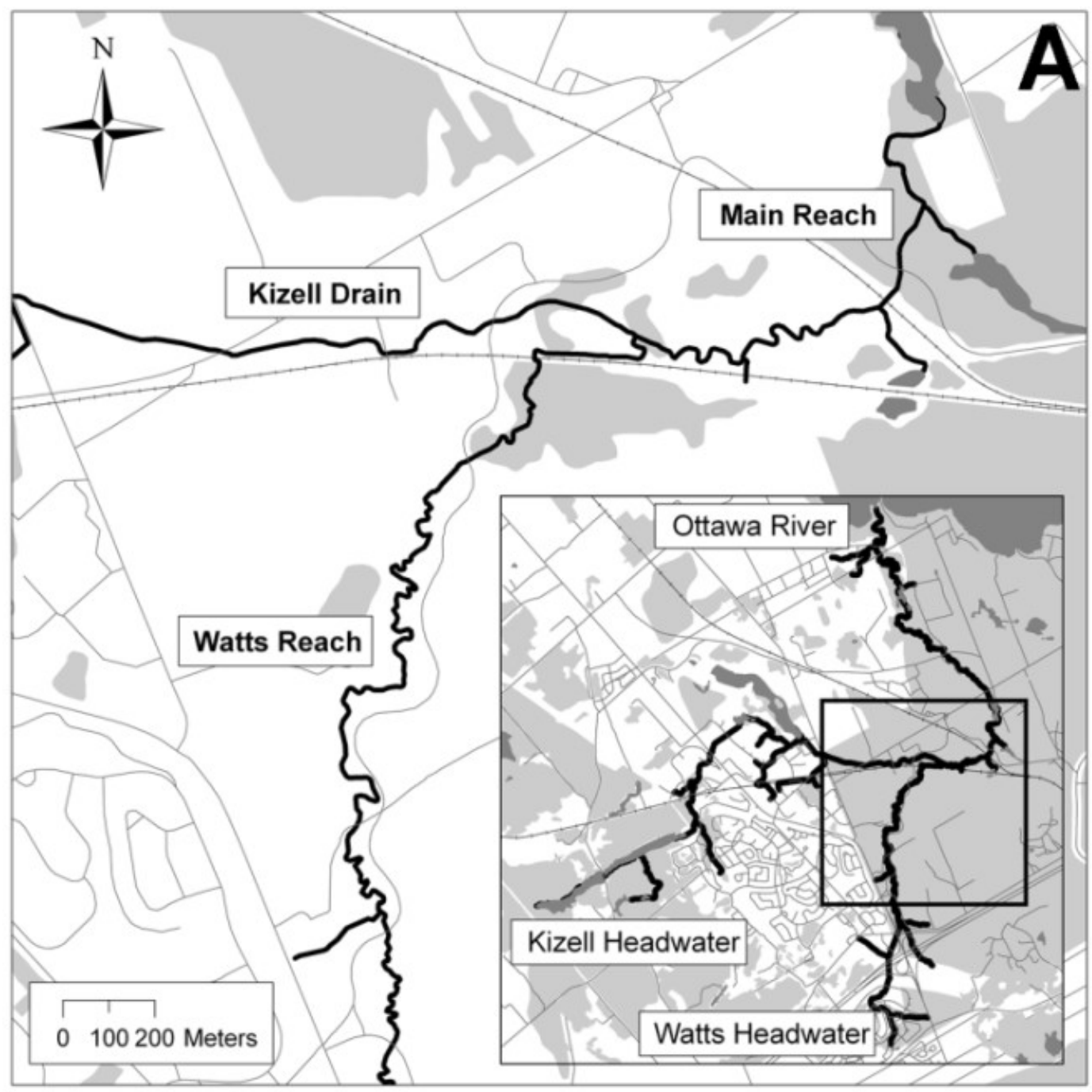

Figure 3.3: The Watts Creek watershed in Kanata, Ontario, Canada where this study took place.

Sampling occurred 150 m upstream from the confluence in both Kizell Drain and Watts Creek.

Water flows from west to east in Kizell Drain and south to north in Watts Creek. Taken from Maarschalk-Bliss (2014). 


\section{Chapter 4: General Discussion}

\subsection{Findings and Implications}

The association between anthropogenic disturbances, resulting in habitat degradation, and the aquatic ecosystem have been well studied in some aspects. The main focus of these studies are community (i.e. fish, macroinvertebrates, etc.) structure (e.g. Berkman and Rabeni 1987; Sponseller et al. 2001; Allan 2004; Maarschalk-Bliss 2014), with less work being done on individual-level metrics (e.g. physiological effects; see Jeffrey et al. In Press). Of late, there has been increasing interest in how GCs act as indicators of individual condition while serving as biomarkers for changing environments (Dantzer et al. 2014). GCs may also help to mechanistically link changes in biodiversity to alterations in the natural environment. Relative to other taxa, however, fish remain less studied in this new area of interest. Due to recent advances in sampling techniques (Busch and Hayward 2009), it has become a relatively simple procedure to measure GC levels from animals in the field. Despite this, many studies still occur during the summer (or near-summer) months due to weather and convenience, leaving much to be discovered about seasonal variation in endocrine responses. Throughout this thesis I evaluated the relationship between ecological factors and the GC stress response in freshwater fishes. In Chapter 2, pumpkinseed from littoral and limnetic collection sites were exposed to a standardized stressor and then assigned to recovery bins varying in habitat complexity and conspecific density. Multiple samples were taken from each fish, allowing for GC and glucose baseline, maximum, and responsiveness to be quantified. In Chapter 3, the association between habitat quality and baseline and maximum GCs was investigated in central mudminnow from two connected streams differing in habitat quality. 
Understanding the mechanisms behind observed patterns in animal abundance is important in a conservation context. For conservation strategies to be effective, it is not enough that we know that a species population is declining. Understanding the mechanisms behind observed patterns (i.e. decreased biodiversity) enables us to identify potential causes for current dilemmas and foresee other consequences that may arise (Wikelski and Cooke 2006). Studies linking the physiological mechanisms behind species decline and habitat degradation are of particular importance in freshwater habitats. It is estimated that approximately $40 \%$ of the global fish diversity lives in freshwater habitats (Lundberg et al. 2000; Dudgeon et al. 2006), yet freshwater systems are one of the most affected by human activities (Dudgeon et al. 2006; Vörösmarty 2010). In my thesis, it was found that habitat quality and conspecific density generally did not have an effect on baseline or maximum GC levels and that time of year did have a significant effect on baseline and maximum GCs. In Chapter 2, pumpkinseed showed no relationship between baseline and maximum glucose and cortisol concentrations and habitat complexity or conspecific density. There was, however, a significant effect of sampling site on maximum glucose, maximum cortisol and glucose responsiveness in the habitat complexity experiment which was run a few days earlier than the conspecific density experiment. This difference between the two experiments may point towards a seasonal influence on the stress response in pumpkinseed that was not further examined in this study. In Chapter 3, central mudminnow did not show a difference in baseline or maximum cortisol levels between the two streams that differed in habitat quality but did show a significant difference in both baseline and maximum cortisol levels across seasons. Winter and spring baseline cortisol levels were significantly higher than fall and summer and spring maximum baseline cortisol levels were significantly higher than the summer. Further work would need to be done to determine the 
influence habitat quality, crowding, and polymoyphism have on the GC stress response in fish but these studies, particularly Chapter 3, indicate that season correlates with variations in baseline and maximum GCs.

Using physiological measures, such as GCs, as indicators of individual health and condition is not uncommon but using these measures to address larger ecological and conservation issues is a quickly emerging field (i.e conservation physiology; Wikelski and Cooke 2006). Both chapters of this thesis did not report a difference in cortisol concentrations between individuals from varying habitat quality. Chapter 2 investigated the influence of habitat complexity, using a grading system of increasingly more complex substrate and vegetation, on the GC response. Very few studies (but see Barcellos et al. 2009) have examined relationships between levels of habitat complexity and GCs but future studies would do more to inform us on whether the lack of variation in GCs is due to the species in question (pumpkinseed) or perhaps is a general trend seen across teleosts. Similarly, Chapter 3 demonstrated no significant difference in GCs between two streams of different habitat quality. Comparable results were found in other studies using generalist species (e.g. creek chub [Blevins et al. 2013]; central mudminnow [Chapman 2014]). It has been hypothesized that more robust species, typically the species in greater abundance in a degraded system, may be inadequate bioindicators as they are less affected by the degraded habitat (Chapman 2014). Though little statistical significance was observed, Chapter 2 of this thesis does show trends indicating that polymorphic species may differ in their response to an environmental challenge. If future studies support this trend then it is important for conservation managers to treat every situation and species individually. General observations can be helpful in a conservation setting but past studies, and this study, indicate that many factors can influence the stress response (Dantzer et al. 2014). Not all species, nor all 
members of the same species, respond the same to an environmental stressor or, conversely, to restoration attempts. Additionally, the relationship between the season and the stress response in fish can be very useful for environmental managers to inform decisions regarding the timing of human activity. Chapter 3 of this thesis showed a significant effect of season on the baseline and maximum cortisol levels in central mudminnow. Other studies (e.g.Wingfield and Grimm 1977; Pankhurst and Sharples 1992; Wingfield et al. 1994) have found similar results.

In a management context, the relationship between season and GCs suggests that careful consideration should be given to planned anthropogenic disturbances (e.g. construction) and, where possible, these events should be postponed to the time of year when they would cause the least harm to the species in the area. This is particularly important in locations where human disturbance will occur but is under protection, such as Watts Creek, which is managed by the NCC. To do this, studies would need to be done in the area prior to any planned human activity (which is rarely done [Wikelski and Cooke 2006]) to determine what time of year the community as a whole is more sensitive to environmental challenges. Ideally, a variety of species, including those more sensitive as well as more robust species, should be used to determine these baseline measurements (Chapman 2014). In addition to this, follow up studies in the area should be conducted to determine any changes in community structure or species' physiological responses that may have occurred as a result. Any changes in physiological measures may provide environmental managers with an early indication that a species has been negatively affected and present the opportunity to quickly rectify the situation. Physiological measures, including GCs, have potential to link environmental disturbances to species' fitness and survival and have potential to be very valuable to conservation efforts (Wikelski and Cooke 2006; Dantzer et al. 2014). However, recent speculation is that simply measuring cortisol levels may not be a good 
enough indicator of the overall stress response (Breuner et al. 2013) as much variation in findings for studies focusing solely on cortisol levels remains unexplained (Breuner et al. 2008; Bonier et al. 2009b). As outlined by Breuner and colleagues (2013), measures of downstream components of the stress response (changes that occur following cortisol release) such as glucose, free fatty acids, red blood cell volume, sex hormones, immunosuppression, oxidative stress, telomere length, acute phase proteins, and body mass may be critical additions to future studies of the stress response. These downstream components are another link between changes in environmental condition and the resulting physiological and behavioural changes in an organism.

\subsection{Future Directions}

There is still much to be learned in the field of GCs and the associated ecological correlates. In order to successfully use GCs as tools in a conservation context more case studies are needed to reveal general trends if we expect to interpret data correctly. In Chapter 2, pumpkinseed GC levels were found to have no correlation with habitat complexity or conspecific density. Further research on the effects of habitat quality on the stress response in wild fishes will help identify if a general trend in teleost fish does exist. Chapter 2 also displayed that there may be a difference in the stress response between morphs of a polymorphic species. Colour morphs (e.g. Pryke et al. 2012) and reproductive morphs (e.g. Knapp and Neff 2007) have both exhibited variations in baseline cortisol concentrations. Future work on species with validation of existing polymorphism (either through euthanizing species or using a species with a more visible morph) would assist in revealing a trend, if present. If this trend does exist then species with polymorphisms should be treated separately when interpreting future physiological data. Sex of the study species was not recorded throughout this thesis and, therefore, fish were 
statistically analysed for both chapters as a whole population. Sex is known to be a factor that influences the stress response (e.g. Lance et al. 2001; Strasser and Heath 2013) and could account for some of the variation seen in the cortisol measures. When possible, future studies should aim to identify sex of individuals in addition to other factors being tested.

In Chapter 3, central mudminnow showed a distinct difference in GC values across seasons but not between two different habitats. The results for the habitat portion of this experiment could be due to the chosen species, as it is a generalist that may not respond as drastically to stressors. Future research in the area should be done with another species of a higher sensitivity to investigate how the habitat quality influences their GC levels. If more sensitive species do show a difference in stress response between the two streams it is possible that the more susceptible species are being negatively impacted by the degradation while other, more hardy species are not. This will assist in future management practices as some species may be inappropriate to use as bioindicators of degraded habitats (Chapman 2014). The difference in GC concentrations demonstrated that both baseline and maximum cortisol levels were the highest in the spring. Studies investigating GCs with multiple sampling events in the spring while incorporating individual reproductive state would help reveal if this increase is associated with the warming of temperatures or the commencement of the breeding season. These findings would guide future management away from planning anthropogenic disturbances during times of the year when it could detrimentally affect a species.

\subsection{Conclusion}

Using physiological indices, such as GCs, to inform conservation decisions is becoming rapidly more common. With more case studies on the topic, our ability to inform these decisions only improves. Through my research I have demonstrated that there are multiple factors 
associated with the stress response in free-living animals. Species' polymorphism and season are two promising correlates that should be considered when interpreting future data. Future studies on the stress response with respect to polymorphic species, habitat quality, and season will further our understanding in this topic and assist in conservation efforts. 


\section{References}

Allan J.D. 2004. Landscape and riverscapes: the influence of land use on stream ecosystems. Annu Rev Ecol Evol System 35: 257-284.

Allen P.J., C.C. Barth, S.J. Peake, M.V. Abrahams, and W.G. Anderson. 2009. Cohesive social behaviour shortens the stress response: the effects of conspecifics on the stress response in lake sturgeon Acipenser fulvescens. J Fish Biol 74: 90-104.

Angelier F. and J.C. Wingfield. 2013. Importance of the glucocorticoid stress response in a changing world: theory, hypotheses and perspectives. Gen Comp Endocr 190: 118-128.

Archard G.A., R.L. Earley, A.F. Hanninen, and V.A. Braithwaite. 2012. Correlated behaviour and stress physiology in fish exposed to different levels of predation pressure. Funct Ecol 26: 637-645.

Baker M.R., K.S. Gobush, and C.H. Vynne. 2013. Review of factors influencing stress hormones in fish and wildlife. J Nat Conserv 21(5): 309-318.

Barcellos L.J.G., L.C. Kreutz , R.M. Quevedo, J.G.S. da Rosa, G. Koakoski, L. Centenaro, and E. Pottker. 2009. Influence of color background and shelter availability on jundiá (Rhamdia quelen) stress response. Aquaculture 288: 51-56.

Bauer C.M., N.K. Skaff, A.B. Bernard, J.M. Trevino, J.M. Ho, L.M. Romero, L.A. Ebensperger, and L.D. Hayes. 2013. Habitat type influences endocrine stress response in the degu (Octodon degus). Gen Comp Endocr 186: 136-144.

Berkman H.E.and C.F. Rabeni. 1987. Effect of siltation on stream fish communities. Environ Biol Fish 18:285-294.

Blevins Z.Q. 2012. Land use drives the physiological properties of a stream fish (Master's 
thesis, University of Illinois, Urbana, Illinois, USA). Retrieved from https://www.ideals.illinois.edu/bitstream/handle/2142/34486/Blevins_Zachary.pdf?seque nce $=1$

Blevins Z.W., D.H. Wahl, and C.D. Suski. 2014. Reach-scale land use drives the stress responses of a resident stream fish. Physiol Biochem Zool 87(1): 113-124.

Bliss S.M., J.D. Midwood, K.M. Stamplecoskie, and S.J. Cooke. 2015. Seasonal movements and residency of small-bodied fish in a north temperate urban watershed demonstrate connectivity between a stream and stormwater drain. Hydrobiologia 742(1): 327-338.

Bonga S.W. 1997. The stress response in fish. Physiol Rev 77(3): 591-625.

Bonier F., P.R. Martin, I.T. Moore, and J.C. Wingfield. 2009a. Do baseline glucocorticoids predict fitness? Trends Ecol Evol 24: 634-642.

Bonier F., I.T. Moore, P.R. Martin, and R.J. Robertson. 2009b. The relationship between fitness and baseline glucocorticoids in a passerine bird. Gen Comp Endocr 163: 208-213.

Boonstra R. 2013. The ecology of stress: a marriage of disciplines. Funct Ecol 27: 7-10.

Breuner C.W. and M. Orchinik M. 2001. Seasonal regulation of membrane and intracellular corticosteroid receptors in the house sparrow brain. J Neuroendocrinol 13: 412-420.

Breuner C.W., S.H. Patterson, and T.P. Hahn. 2008. In search of relationships between the acute adrenocortical response and fitness. Gen Comp Endocr 157: 288-295.

Breuner C.W., B. Delehanty, and R. Boonstra. 2013. Evaluating stress in natural populations of vertebrates: total CORT is not good enough. Funct Ecol 27(1): 24-36.

Brown R.S., S.S. Stanislawski, and W.C. Mackay. 1994. Effects of frazil ice on fish. Workshop on environmental aspects of river ice. Environment Canada, National Hydrology Research Institute Symposium 12: 261-277. 
Busch D.S. and L.S. Hayward. 2009. Stress in a conservation context: a discussion of glucocorticoid actions and how levels change with conservation-relevant variables. Biol Conserv 142: 2844-2853.

Calow P. and V.E. Forbes. 1998. How do physiological responses to stress translate into ecological and evolutionary processes? Comp Biochem Phys 120(1): 11-16.

Chapman J.M. 2014. Effects of watershed land use on the seasonal energy dynamics, condition, and parasite communities of stream fish (Master's thesis, Carleton University, Ottawa, ON, Canada). Retrieved from https://curve.carleton.ca/28d46cb1-b153-4023-8d8027bfeb7a3803

Chomyshyn L., S.H. McConnachie, and S.J. Cooke. 2011. Evaluation of water entry into the coelom and different levels of aseptic technique during surgical implantation of electronic tags in freshwater fish. Rev Fish Biol Fisher 21(1): 61-70.

Chrousos G.P. and P.W. Gold. 1992. The concepts of stress and stress system disorders. Overview of physical and behavioural homeostasis. J Am Med Assoc 267: 1244-1252.

Coe C.L., S.P. Mendoza, and S. Levine. 1979. Social status constrains the stress response in the squirrel monkey. Physiol Behav 23: 633-638.

Cook K.V., C.M. O’Connor, S.H. McConnachie, K.M. Gilmour, and S.J. Cooke. 2012. Condition dependent intra-individual repeatability of stress-induced cortisol in a freshwater fish. Comp Biochem Phys A 161: 337-343.

Cooke S.J., L. Sack, C.E. Franklin, A.P. Farrell, J. Beardall, M. Wikelski, and S.L. Chown. 2013. What is conservation physiology? Perspectives on an increasingly integrated and essential science. Conserv Physiol 1(1): $\cot 001$.

Cooperman M.D., J.M. Reed, and L.M. Romero. 2004. The effects of terrestrial and breeding 
densities on corticosterone and testosterone levels in spotted salamanders, Ambystoma maculatum. Can J Zool 82: 1795-1803.

Cousineau A., J.D. Midwood, K. Stamplecoskie, G. King, C.D. Suski, and S.J. Cooke. 2014. Diel patterns of baseline glucocorticoids and stress responsiveness in a teleost fish (bluegill, Lepomis macrochirus). Can J Zool 92: 417-421.

Crossin G., O.P. Love, S.J. Cooke, T. Williams. In Press. Glucocorticoid manipulations in freeliving animals: considerations of dose delivery, life-history context, and reproductive state. Funct Ecol 00:000-000.

Cunjak R.A. 1996. Winter habitat of selected stream fishes and potential impacts from land-use activity. Can J Fish Aquat Sci 53: 267-282.

Dale V.H. and S.C. Beyeler. 2001. Challenges in the development and use of ecological indicators. Ecol Indic 1(1): 3-10.

Dantzer B., A.E. Newman, R. Boonstra, R. Palme, S. Boutin, M.M. Humphries, and A.G. McAdam. 2013. Density triggers maternal hormones that increase adaptive offspring growth in a wild mammal. Science 340: 1215-1217.

Dantzer B., Q.E. Fletcher, R. Boonstra, and M.J. Sheriff. 2014. Measures of physiological stress: a transparent or opaque window into the status, management and conservation of species? Conserv Physiol 2 (1): cou023 doi:10.1093/conphys/cou023

de Jesus E.G., T. Hirano, and Y. Inui. 1991. Changes in cortisol and thyroid hormone concentrations during early development and metamorphosis in the Japanese flounder, Paralichthys olivaceus. Gen Comp Endocr 82(3): 369-376.

Dudgeon D., A.H. Arthington, M.O. Gessner, Z.I. Kawabata, D.J. Knowler, C. Lévêque, R.J. 
Naiman, A.H. Prieur-Richard, D. Soto, M.L.J. Stiassny, and C.A. Sullivan. 2006.

Freshwater biodiversity: importance, threats, status and conservation challenges. Biol Rev 81: 163-182.

Easterling D.R., G.A. Meehl, C. Parmesan, S.A. Changnon, T.R. Karl, and L.O. Mearns. 2000. Climate extremes: observations, modeling, and impacts. Science 289(5487): 2068-2074.

Evans M.R., M.L. Roberts, K.L. Buchanan, and A.R. Goldsmith. 2006. Heritability of corticosterone response and changes in life history traits during selection in the zebra finch. J Evolution Biol, 19: 343-352.

Fefferman N.H. and L.M. Romero. 2013. Can physiological stress alter population persistence? A model with conservation implications. Conserv Physiol 1(1): cot012.

Feist G., C.B. Schreck, M.S. Fitzpatrick, and J.M. Redding. 1990. Sex steroid profiles of coho salmon (Oncorhynchus kisutch) during early development and sexual differentiation. Gen Comp Endocr 80(2): 299-313.

Folch J., M. Lees, and G.H. Sloane-Stanley. 1957. A simple method for the isolation and purification of total lipids from animal tissues. J Biol Chem 226(1): 497-509.

Fusani L. 2008. Endocrinology in field studies: problems and solutions for the experimental design. Gen Comp Endocr 157: 249-253.

Gamperl A., M. Vijayan, and R. Boutilier. 1994. Experimental control of stress hormone levels in fishes: techniques and applications. Rev Fish Biol Fisher 4: 215-225.

Gesquiere L.R., M. Khan, L. Shek, T.L. Wango, E.O. Wango, S.C. Alberts, and J. Altmann. 2008. Coping with a challenging environment: effects of seasonal variability and reproductive status on glucocorticoid concentrations of female baboons (Papio cynocephalus). Horm Behav 54: 410-416. 
Gillespie G.J. and M.G. Fox. 2003. Morphological and life-history differentiation between \ littoral and pelagic forms of pumpkinseed. J Fish Biol 62: 1099-1115.

Gilmour K.M., J.D. DiBattista, and J.B. Thomas. 2005. Physiological causes and consequences of social status in salmonid fish. Integr Comp Biol 45: 263-273.

Goldstein R.M. and M.R. Meador. 2005. Multilevel assessment of fish species traits to evaluate habitat degradation in streams of the upper Midwest. N Am J Fish Manage 25: 180-194.

Haddy J.A. and N.W. Pankhurst. 1999. Stress-induced changes in concentrations of plasma sex steroids in black bream. J Fish Biol 55(6): 1304-1316.

Hawkley L.C., S.W. Cole, J.P. Capitania, G.J. Norman, and J.T. Cacioppo. 2012. Effects of social isolation on glucocorticoid regulation in social mammals. Horm Behav 62: 314323.

Hennessy M.B., S. Kaiser, and N. Sachser. 2009. Social buffering of the stress response: Diversity, mechanisms and functions. Front Neuroendocrin 30: 470-482.

Homyack J.A. 2010. Evaluating habitat quality of vertebrates using conservation physiology tools. Wildlife Res 37(4): 332-342.

Hontela A., J.B. Rasmussen, C. Audet, G. Chevalier. 1992. Impaired cortisol stress response in fish from environments polluted by PAHs, PCBs, and mercury. Arch Environ Con Tox 22(3): 278-283.

Hopkins W.A. and S.E. DuRant. 2011. Innate immunity and stress physiology of eastern hellbenders (Cryptobranchus alleganiensis) from two stream reaches with differing habitat quality. Gen Comp Endocr 174(2): 107-115.

Huey R.B. 1991. Physiological consequences of habitat selection. Am Nat S91-S115.

Husak J.F. and I.T. Moore. 2008. Stress hormones and mate choice. Trends Ecol Evol 23: 532- 
534.

Jeffrey J.D., C.T. Hasler, J.M. Chapman, S.J. Cooke, and C.D. Suski. In Press. Linking landscape-scale disturbances to stress and condition of fish: implications for restoration and conservation. Integr Comp Biol 00:000-000.

Johnson M.D. 2007. Measuring habitat quality: a review. The Condor 109(3): 489-504.

Johnstone C.P., R.D. Reina, and A. Lill. 2012. Interpreting indices of physiological stress in freeliving vertebrates. J Comp Physiol B 182(7): 861-879.

Keast A. 1980. Food and feeding relationships of young fish in the first weeks after the beginning of exogenous feeding in Lake Opinicon, Ontario. Environ Biol Fish 5: 305314.

King G.D. 2014. Nutritional condition and stress response of fishes along a gradient of habitat quality in the St. Lawrence River: Physiological consequences of anthropogenic habitat degradation (Master's thesis, University of Illinois, Urbana, Illinois, USA). Retrieved from http://www.fecpl.ca/wp-content/uploads/2015/01/Thesis-G.D.-King-Final.pdf

Kitaysky A.S., J.C. Wingfield, and J.F. Piatt. 1999. Dynamics of food availability, body condition and physiological stress response in breeding black-legged kittiwakes. Funct Ecol 13: 577-584.

Knapp R. and B.D. Neff. 2007. Steroid hormones in bluegill, a species with male alternative reproductive tactics including female mimicry. Biol Lett 3: 628-632.

Lance V.A., J.S. Grumbles, and D.C. Rostal. 2001. Sex differences in plasma corticosterone in desert tortoises, Gopherus agassizii, during the reproductive cycle. J Exp Zool 289: 285289.

Landys M.M., M. Ramenofsky, and J.C. Wingfield. 2006. Actions of glucocorticoids at a 
seasonal baseline as compared to stress-related levels in the regulation of periodic life processes. Gen Comp Endocr 148: 132-149.

Love O.P., D.M. Bird, and L.J. Shutt. 2003. Corticosterone levels during post-natal development in captive American kestrels (Falco sparverius). Gen Comp Endocr 130: 135-141.

Lundberg G., M. Kottelat, G.R. Smith, M.L.J. Stiassny, and A.C. Gill. 2000. So many fishes, so little time: an overview of recent icthyological discovery in continental waters. Ann Missouri Bot Gard 87: 26-62.

Maarschalk-Bliss S.M. 2014. Seasonal variation in assemblage structure and movement of small stream fish in an urban environment (Master's thesis, Carleton University, Ottawa, ON, Canada). Retrieved from http://www.fecpl.ca/wp-content/uploads/2013/05/SBliss_ MScThesis_Final.pdf

Marra P.P. and R.L. Holberton. 1998. Corticosterone levels as indicators of habitat quality: effects of habitat segregation in a migratory bird during the non-breeding season. Oecologia 116(1-2): 284-292.

Martin-Bergmann K.A. and J.H. Gee. 1985. The central mudminnow, Umbra limi (Kirtland), a habitat specialist and resource generalist. Can J Zoolog 63(8): 1753-1764.

Meyer J.L., M.J. Paul, and W.K. Taulbee. 2005. Stream ecosystem function in urbanizing landscapes. J N Am Benthol Soc 24(3): 602-612.

Mitton C.J.A. and D.G. McDonald. 1994. Consequences of pulsed DC electrofishing and air exposure to rainbow trout (Oncorhynchus mykiss). Can J Fish Aquat Sci 51(8): 17911798.

Nagrodski A., C.D. Suski, and S.J. Cooke. 2013. Health, condition, and survival of creek chub 
(Semotilus atromaculatus) across a gradient of stream habitat quality following an experimental cortisol challenge. Hydrobiologia 702: 283-296.

Newcomb Homan R., J.V. Regosin, D.M. Rodrigues, J.M. Reed, B.S. Windmiller, and L.M. Romero. 2003. Impacts of varying habitat quality on the physiological stress of spotted salamanders (Ambystoma maculatum). Anim Conserv 6: 11-18.

Norris D.O., S. Donahue, R.M. Dores, J.K. Lee, T.A. Maldonado, T. Ruth, J.D. Woodling. 1999. Impaired adrenocortical response to stress by brown trout, Salmo trutta, living in metalcontaminated waters of the Eagle River, Colorado. Gen Comp Endocr 113(1): 1-8.

Osenberg C.W., G.G. Mittelbach, and P.C. Wainwright. 1992. Two stage life histories in fish: the interaction between juvenile competition and adult diet, performance, and morphology. Ecology 73: 255-267.

Pankhurst N.W. and D.F. Sharples. 1992. Effects of capture and confinement on plasma cortisol concentrations in the snapper, Pagrus auratus. Mar Freshwater Res 43(2), 345-355.

Peckham R.S. and C.F. Dineen. 1957. Ecology of the central mudminnow, Umbra limi (Kirtland). Am Midl Nat 222-231.

Pryke S.R., L.B. Astheimer, S.C. Griffith, and W.A. Buttemer. 2012. Covariation in life-history traits: differential effects of diet on condition, hormones, behavior, and reproduction in genetic finch morphs. Am Nat 179: 375-390.

Pullen C.E. 2013. The consequences of retained lures on free swimming fish: physiological, behavioural and fitness perspectives (Master's thesis, Carleton University, Ottawa, ON, Canada). Retrieved from http://www.fecpl.ca/wp-content/uploads/2014/08/CPULLEN _MSc_Thesis_Final-V1_May-16.pdf

Reeder D.M. and K.M. Kramer. 2005. Stress in free-ranging mammals: integrating physiology, 
ecology, and natural history. J Mammal 86(2): 225-235.

Remage-Healey L., E. Adkins-Regan, and L.M. Romero. 2003. Behavioral and adrenocortical responses to mate separation and reunion in the zebra finch. Horm Behav 43: 108-114.

Ricklefs R.E. and M. Wikelski. 2002. The physiology/life-history nexus. Trends Ecol Evol 17: $462-468$.

Robinson B.W., D.S. Wilson, A.S. Margosian, and P.T. Lotito. 1993. Ecological and morphological differentiation of pumpkinseed sunfish in lakes without bluegill sunfish. Evol Ecol 7: 451-464.

Robinson B.W. and D.S. Wilson. 1996. Genetic variation and phenotypic plasticity in a trophically polymorphic population of pumpkinseed sunfish (Lepomis gibbosus). Evol Ecol 10: 631-652.

Romero L.M. 2002. Seasonal changes in plasma glucocorticoid concentrations in free-living vertebrates. Gen Comp Endocr 128: 1-24.

Romero L.M. 2004. Physiological stress in ecology: lessons from biomedical research. Trends Ecol Evol 19: 249-255.

Romero L.M. and J.M. Reed. 2005. Collecting baseline corticosterone samples in the field: is under 3 min good enough? Comp Biochem Phys A 140: 73-79.

Romero L.M., C.J. Meister, N.E. Cyr, G.J. Kenagy, and J.C. Wingfield. 2008. Seasonal glucocorticoid responses to capture in wild free-living mammals. Am J Physiol Regul Integr Comp Physiol 294: R614-R622.

Romero L.M., M.J. Dickens, and N.E. Cyr. 2009. The reactive scope model - a new model integrating homeostasis, allostasis, and stress. Horm Behav 55: 375-389.

Rotllant J. and L. Tort. 1997. Cortisol and glucose responses after acute stress by net handling in 
the sparid red porgy previously subjected to crowding stress. J Fish Biol 51(1): 21-28.

Sapolsky R.M., L.M. Romero, and A.U. Munck. 2000. How do glucocorticoids influence stress responses? Integrated permissive, suppressive, stimulatory, and preparative actions. Endocr Rev 21: 55-89.

Scott W.B. and E.J. Crossman. 1973. Freshwater fishes of Canada. B Fish Res Board Can 184.

Sheriff M.J., B. Dantzer, B. Delehanty, R. Palme, and R. Boonstra. 2011. Measuring stress in wildlife: techniques for quantifying glucocorticoids. Oecologia 166: 869-887.

Sims C.G. and R.L. Holberton. 2000. Development of the corticosterone stress response in young northern mockingbirds (Mimus polyglottos). Gen Comp Endocr 119: 193-201.

Sponseller R., E. Benfield, and H. Valett. 2001. Relationships between land use, spatial scale and stream macroinvertebrate communities. Freshwater Biol 46: 1409-1424.

Stoot L.J., N.A. Cairns, F. Cull, J.J. Taylor, J.D. Jeffrey, F. Morin, J.W. Mandelman, T.D. Clark, and S.J. Cooke. 2014. Use of portable blood physiology point-of-care devices for basic and applied research on vertebrates: a review. Conserv Physiol 2 (1): cou011 doi: 10.1093/conphys/cou011

Strasser E.H. and J.A. Heath. 2013. Reproductive failure of a human-tolerant species, the American kestrel, is associated with stress and human disturbance. J Appl Ecol 50: 912919.

Suorsa P., E. Huhta, A. Nikula, M. Nikinmaa, A. Jantti, H. Helle, and H. Hakkarainen. 2003. Forest management is associated with physiological stress in an old growth forest passerine. P Roy Soc Lond B Bio 270: 963-969.

Tempel D.J. and R.J. Gutierrez. 2003. Fecal corticosterone levels in California spotted owls exposed to low-intensity chainsaw sound. Wildlife Soc B 31: 698-702. 
Vitousek P.M., H.A. Mooney,J. Lubchenco, and J.M. Melillo. 1997. Human domination of Earth's ecosystems. Science 277(5325): 494-499.

Vörösmarty C.J., P.B. McIntyre, M.O. Gessner, D. Dudgeon, A. Prusevich, P. Green, S. Glidden, S.E. Bunn, C.A. Sullivan, C. Reidy Liermann, and P.M. Davies. 2010. Global threats to human water security and river biodiversity. Nature 467(7315): 555-561.

Walker B.G., P.D. Boersma, and J.C. Wingfield. 2005a. Field endocrinology and conservation biology. Integr Comp Biol 45: 12-18.

Walker B.G., J.C. Wingfield, and P.D. Boersma. 2005b. Age and food deprivation affects expression of the glucocorticosteroid stress response in Magellanic penguin (Spheniscus magellanicus) chicks. Physiol Biochem Zool 78: 78-89.

Warren Jr. M. L. 2009. Centrarchid identification and natural history. Centrarchid Fishes Diversity, Biology and Conservation. Blackwell Publishing, West Sussex UK, 375-533.

Wasser S.K., K. Bevis, G. King, and E. Hanson. 1997. Non-invasive physiological measures of disturbance in the northern spotted owl. Conserv Biol 11: 1019-1022.

Wikelski M. and S.J. Cooke. 2006. Conservation physiology. Trends Ecol Evol 21(1): 38-46. Wingfield J.C. and A.S. Grimm. 1977. Seasonal changes in plasma cortisol, testosterone and oestradiol-17 $\beta$ in the plaice, Pleuronectes platessa L. Gen Comp Endocr 31(1): 1-11.

Wingfield J.C., C.M. Vleck, and M.C. Moore. 1992. Seasonal changes of the adrenocortical response to stress in birds of the Sonoran Desert. J Exp Zool 264: 419-428.

Wingfield J.C., P. Deviche, S. Sharbaugh, L.B. Astheimer, R. Holberton, R. Suydam, K. Hunt. 1994. Seasonal changes of the adrenocortical responses to stress in redpolls, Acanthis flammea, in Alaska. J Exp Zool 270(4): 372-380.

Wingfield J.C., D.L. Maney, C.W. Breuner, J.D. Jacobs, S. Lynn, M. Ramenofsky, and R.D. 
Richardson. 1998. Ecological bases of hormone — behavior interactions: the "emergency life history stage”. Am Zool 38: 191-206.

Wingfield J.C. and L.M. Romero. 2001.Adrenocortical responses to stress and their modulation in free-living vertebrates. In: McEwen, B.S., Goodman, H.M. (Eds), Handbook of Physiology; Section 7: The Endocrine System; Volume IV: Coping with the Environment: Neural and Endocrine Mechanisms. Oxford Univ. Press, New York. 211234.

Wingfield J.C. 2005. The concept of allostasis: coping with a capricious environment. J Mammal 86: $248-254$.

Zera A.J. and L.G. Harshman. 2001. The physiology of life history trade-offs in animals. Annu Rev Ecol Syst 95-126. 